\title{
Thymol-loaded PLGA nanoparticles: an efficient approach for acne treatment
}

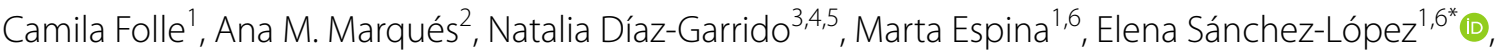 \\ Josefa Badia ${ }^{3,4,5}$, Laura Baldoma ${ }^{3,4,5}$, Ana Cristina Calpena $a^{1,6}$ and Maria Luisa García ${ }^{1,6^{*}}$
}

\begin{abstract}
Background: Acne is a common skin disorder that involves an infection inside the hair follicle, which is usually treated with antibiotics, resulting in unbalanced skin microbiota and microbial resistance. For this reason, we developed polymeric nanoparticles encapsulating thymol, a natural active compound with antimicrobial and antioxidant properties. In this work, optimization physicochemical characterization, biopharmaceutical behavior and therapeutic efficacy of this novel nanostructured system were assessed.

Results: Thymol NPs (TH-NP) resulted on suitable average particle size below $200 \mathrm{~nm}$ with a surface charge around $-28 \mathrm{mV}$ and high encapsulation efficiency (80\%). TH-NP released TH in a sustained manner and provide a slow-rate penetration into the hair follicle, being highly retained inside the skin. TH-NP possess a potent antimicrobial activity against Cutibacterium acnes and minor effect towards Staphylococcus epidermis, the major resident of the healthy skin microbiota. Additionally, the stability and sterility of developed NPs were maintained along storage.

Conclusion: TH-NP showed a promising and efficient alternative for the treatment of skin acne infection, avoiding antibiotic administration, reducing side effects, and preventing microbial drug resistance, without altering the healthy skin microbiota. Additionally, TH-NP enhanced TH antioxidant activity, constituting a natural, preservative-free, approach for acne treatment.
\end{abstract}

Keywords: Acne, Thymol, PLGA nanoparticles, Skin delivery system, Cutibacterium acnes, Skin microbiota, Antimicrobial, Antioxidant

\footnotetext{
*Correspondence: esanchezlopez@ub.edu; marisagarcia@ub.edu

${ }^{1}$ Department of Pharmacy and Pharmaceutical Technology and Physical

Chemistry, Faculty of Pharmacy and Food Sciences, University

of Barcelona, 08028 Barcelona, Spain

Full list of author information is available at the end of the article
} original author(s) and the source, provide a link to the Creative Commons licence, and indicate if changes were made. The images or other third party material in this article are included in the article's Creative Commons licence, unless indicated otherwise in a credit line to the material. If material is not included in the article's Creative Commons licence and your intended use is not permitted by statutory regulation or exceeds the permitted use, you will need to obtain permission directly from the copyright holder. To view a copy of this licence, visit http://creativecommons.org/licenses/by/4.0/. The Creative Commons Public Domain Dedication waiver (http://creativeco mmons.org/publicdomain/zero/1.0/) applies to the data made available in this article, unless otherwise stated in a credit line to the data. 


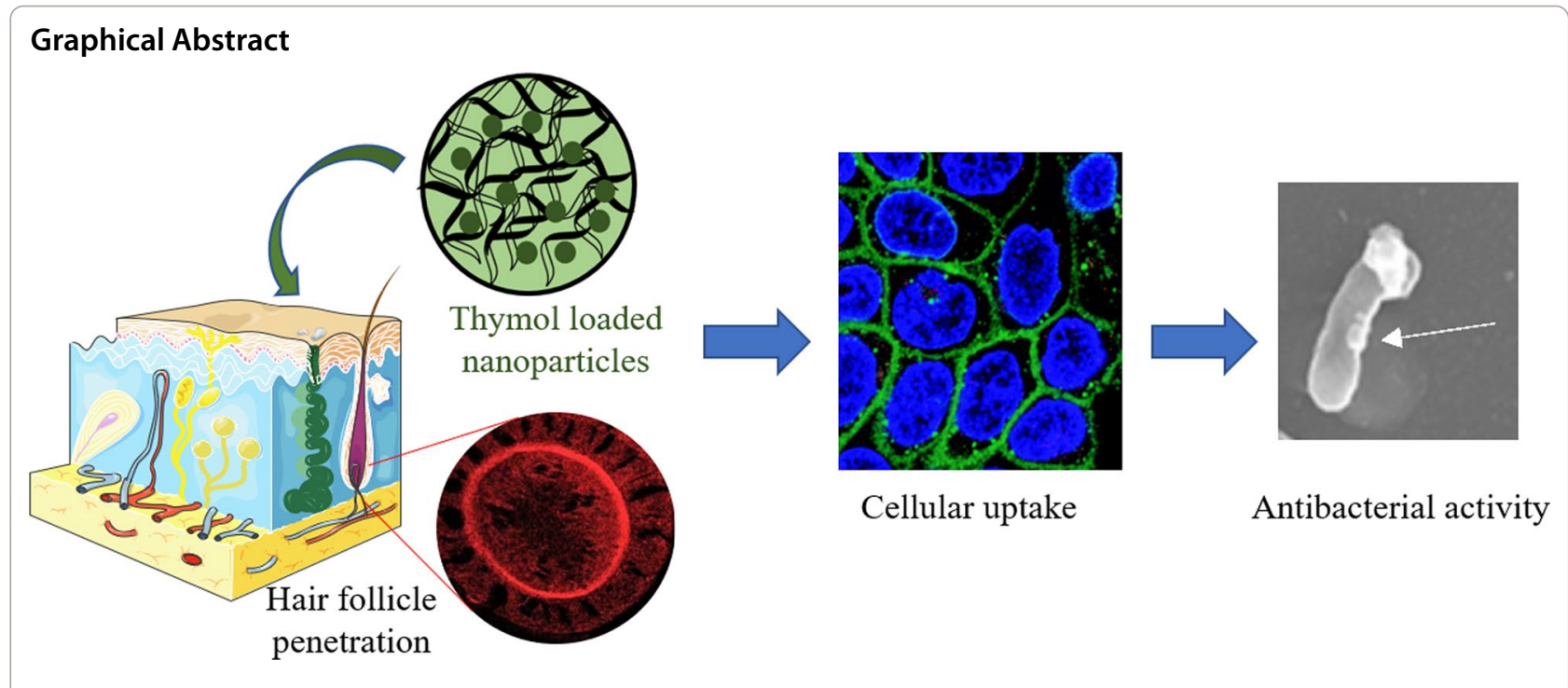

\section{Background}

Acne is a common skin disorder, known as Acne vulgaris, that affects a large number of the population. Several factors, such as hormones, diet, stress and environmental pollution, among others, may contribute to acne development. These factors trigger hyperactivity of sebaceous glands that produce elevated levels of sebum, hyperkeratosis by blockage of the hair follicle and, additionally, contribute to the excessive microbiota reproduction [1].

The skin is divided into three functional layers that surround the hair follicle. The base is found on the dermis-hypodermis junction, just above the fat tissue. Production of sebum occurs in the sebaceous gland, which is located inside the dermis. The upper layers of the epidermis are composed by keratinocyte cells surrounding the hair top-to-bottom. The external skin layer, stratum corneum (SC), protects the skin from the external environment, being considered the main challenge for several topical drugs penetration.

Several microorganisms reside in the skin and can be classified as resident or transient microbiota. They are normally gram-positive bacteria, not regarded as pathogens, which survive longer on intact skin than gram-negative transient species. The protective microbiota functions are believed to confer microbial antagonism activity and nutrient competition for the stability of the dermal ecosystem, preventing the adherence of pathogens and maintaining the skin health balanced [2]. Staphylococcus epidermidis is the most abundant colonizer of human skin and, despite considered a benign microorganism, it is highly present in acne lesions [3]. It is ubiquitously found mainly concentrated on the upper layers of the skin and may have a probiotic function by preventing colonization of pathogenic bacteria such as Staphylococcus aureus [4]. Concerning Cutibacterium acnes, previously known as Propionibacterium acnes, it is a resident bacteria, mainly located surrounding the hair follicle, which is likely to proliferate under unbalanced function of the sebaceous glands, leading to acne development, swelling and inflammation [5]. Hence, C. acnes has a dual activity on the skin microbiota, being a nonpathogen essential for sebum control, as well as an active pathogen on acne infection and inflammation. Additionally, it maintains the acidic $\mathrm{pH}$ of the pilosebaceous follicle by hydrolyzing sebum triglycerides and via propionic acid secretion. Moreover, it has been previously stated that acne might be the result of an unbalanced equilibrium between $C$. acnes and S. epidermidis [6]. Therefore, a suitable treatment for acne should provide good antimicrobial activity but acquiring mild effect to the healthy microbiota.

Nanoparticles (NP) are a good approach to enter the hair follicle and release the antimicrobial agent directly in the acne lesion $[7,8]$. The fat deposit on the subcutaneous tissue may behave as a deep compartment for the drug, delaying its entry in the blood circulation [9]. Polymeric nanospheres of poly(lactic-co-glycolic) acid (PLGA), form a matrix structure containing the entrapped active compound. PLGA, approved by the Food and Drug Administration (FDA), is known to be safe for dermal applications due to its bioavailability and biodegradable profile. One of the advantages of PLGA NPs entrapping highly volatile compounds is that their production can be performed at room temperature. 
Moreover, nanotechnology also has several advantages in dermal drug delivery since small particle diameters tend to penetrate into the deep skin (DS), withdraw the drug in a controlled manner and be mainly retained in the deeper layers $[8,10]$. The size and flexibility of PLGA NPs enable entry into host cells via endocytosis, thus allowing intracellular release. In addition, they are easily phagocytosed by host phagocytes [11].

In this area, several clinical assays highlight the successful combination of nutraceuticals/cosmetic compounds and their encapsulation in nanostructured systems for topical acne treatment. In this area, AbdAllah and colleagues showed successful reduction of acne inflammatory lesions with nicotinamide loaded chitosan nanoparticles [12]. Furthermore, quercetin has also been encapsulated into nanovesicles and proven to be effective both as antibacterial and anti-inflammatory [13].

Among the wide range of nutraceutical compounds, thymol $(\mathrm{TH})$, is a multifunctional monoterpene of aromatic phenolic structure, with a volatile compound with a strong and characteristic odor. It can be found naturally occurring in plant extracts or on its white crystalline synthetic form. It is found in Lamiaceae plant species, especially oreganos and thymes, which present antimicrobial, antioxidant and antiseptic properties [14-17]. It is considered safe in cosmetic formulations up to $0.5 \%$, according to the Cosmetic Ingredients Review (CIR) and it is used as preservative in cosmetics and foods [18]. Moreover, TH antioxidant and antimicrobial properties allow cosmetic products to avoid the use of other chemical compounds as preservatives. The effects of $\mathrm{TH}$ are largely attributed to its antioxidant properties, via free radical scavenging thus enhancing endogenous antioxidant activities and chelation of metal ions [19]. The antioxidant activity provides an interesting therapeutic approach to restore skin homeostasis, maintaining its internal conditions relatively constant and stable, modulates the stratum corneum SC barrier function and prevents skin irritation [20].

Bacterial survival depends on membrane lipid homeostasis and the ability to adjust the lipid composition of bacterial cells in different environments. There are biochemical processes that underlie adjustments and are responsible for membrane phospholipid homeostasis in bacteria, controlling the movement of substances across the cell membrane [21]. These processes depend on proteins embedded in a lipid matrix that closely approximates a phospholipid bilayer.

The hydrophobic nature of $\mathrm{TH}$ facilitates its interaction with the lipidic bacterial membrane via direct binding with biomolecules, such as proteins, providing strong antimicrobial effect by altering its morphology and leading to bacterial death [22, 23]. Disruption of bacterial membrane will lead to cell disfunction and apoptosis, resulting in loss of intracellular contents. Some authors suggested that $\mathrm{TH}$ antibacterial action is due to the increased permeability of bacterial cell membranes [24]. However, other studies suggest that $\mathrm{TH}$ is responsible for the inactivation of enzymes implicated in synthesis of structural constituents [14]. The extent of bacteria membrane damage induced by a compound could be related to its intrinsic hydrophobicity. In the other hand, the slight hydrophilicity could enhance diffusion through the extracellular polysaccharide matrix and cause destabilization of bacterial biofilms [16].

With the aim to increase and prolong skin penetration into the hair follicle, without affecting the entire microbiota, PLGA NP containing TH (TH-NP) have been developed and optimized using the design of experiments (DoE) approach. Physicochemical characterization and biopharmaceutical behavior of optimized TH-NPs have been determined. Cytotoxicity, cellular uptake and antioxidant activity of TH-NP have also been assessed in human keratinocytes cell-line $(\mathrm{HaCaT})$. In addition, antimicrobial therapeutic efficacy of this colloidal system was evaluated in vitro and ex vivo.

\section{Results}

\section{Formulation characterization and optimization}

The optimization of TH-NP was obtained by developing a full composite factorial design of five levels and three factors. Studied independent variables were the amount of TW and TH as well as $\mathrm{pH}$ formulation. The latter was chosen due both to Thymol pKa (pKa 10.6) which, as previously reported in other studies, can influence in the $\mathrm{EE}$ $[25,26]$.

The results of the DoE physicochemical characterization and the entrapment efficiency of TH-NPs are shown in Table 1 . The average particle size ( $\mathrm{Zav}$ ) values ranged from 162 to $235 \mathrm{~nm}$, being the polydispersity index (PI) comprised between 0.06 and 0.12 . Based on the criteria for monodispersed systems $(\mathrm{PI}<0.1)$, all the formulations presented homogeneity [27]. The surface charge of TH-NP, measured as Z-potential (ZP), ranged from - 22 to $-31 \mathrm{mV}$. This negative $\mathrm{ZP}$ is associated with negative surface charge associated with PLGA, the main NPs compound $[25,28-30]$. Moreover, ZP is related to the stability of colloidal dispersions, for this reason, the developed formulations with values closest to $-30 \mathrm{mV}$, were considered the most stable. The encapsulation efficiency (EE) of designed formulations ranged from 71 to $83 \%$.

Surface response charts of the DoE, performed by Statgraphics ${ }^{\circledR}$ software, are shown in Fig. 1. The statistical analysis (ANOVA) only presented significant differences for the particle size $(\mathrm{p}<0.01)$, influenced by both, $\mathrm{pH}$ of the aqueous phase and ratio of surfactant/pH (Fig. 1A). 
Table 1 Values of the $2^{3}+$ star central composite factorial design, parameters, and responses

\begin{tabular}{|c|c|c|c|c|c|c|c|}
\hline & \multicolumn{3}{|c|}{ Independent variables } & \multicolumn{4}{|c|}{ Dependent variables/responses } \\
\hline & TH & TW & $\mathrm{pH}$ & $\mathrm{Z}_{\mathrm{av}}(\mathrm{nm})$ & PI & $\mathrm{ZP}(\mathrm{mV})$ & EE (\%) \\
\hline \multicolumn{8}{|c|}{ Factorial points } \\
\hline F1 & -1 & -1 & -1 & $217.9 \pm 1.2$ & $0.112 \pm 0.001$ & $-30.7 \pm 0.9$ & $76.35 \pm 1.53$ \\
\hline $\mathrm{F} 2$ & 1 & -1 & -1 & $234.9 \pm 2.1$ & $0.093 \pm 0.004$ & $-29.9 \pm 0.4$ & $79.16 \pm 0.18$ \\
\hline F3 & -1 & 1 & -1 & $176.2 \pm 1.0$ & $0.075 \pm 0.023$ & $-27.7 \pm 1.3$ & $76.67 \pm 2.17$ \\
\hline F4 & 1 & 1 & -1 & $174.0 \pm 0.6$ & $0.081 \pm 0.012$ & $-28.3 \pm 0.8$ & $80.07 \pm 3.65$ \\
\hline F5 & -1 & -1 & 1 & $162.0 \pm 0.4$ & $0.072 \pm 0.011$ & $-26.2 \pm 0.3$ & $79.64 \pm 3.79$ \\
\hline F6 & 1 & -1 & 1 & $163.5 \pm 1.4$ & $0.071 \pm 0.009$ & $-23.6 \pm 0.5$ & $73.52 \pm 1.83$ \\
\hline F7 & -1 & 1 & 1 & $183.9 \pm 0.4$ & $0.087 \pm 0.020$ & $-29.5 \pm 0.1$ & $78.41 \pm 2.51$ \\
\hline F8 & 1 & 1 & 1 & $172.4 \pm 1.1$ & $0.094 \pm 0.009$ & $-26.6 \pm 0.3$ & $76.60 \pm 5.60$ \\
\hline \multicolumn{8}{|c|}{ Axial points } \\
\hline F9 & 1.68 & 0 & 0 & $174.2 \pm 0.6$ & $0.061 \pm 0.018$ & $-25.2 \pm 0.4$ & $77.01 \pm 3.07$ \\
\hline F10 & -1.68 & 0 & 0 & $176.7 \pm 1.1$ & $0.083 \pm 0.033$ & $-23.6 \pm 0.3$ & $73.55 \pm 2.93$ \\
\hline F11 & 0 & 1.68 & 0 & $187.1 \pm 0.8$ & $0.024 \pm 0.006$ & $-23.1 \pm 0.6$ & $71.38 \pm 0.62$ \\
\hline $\mathrm{F} 12$ & 0 & -1.68 & 0 & $167.4 \pm 2.1$ & $0.046 \pm 0.021$ & $-26.1 \pm 0.4$ & $76.92 \pm 2.47$ \\
\hline F13 & 0 & 0 & 1.68 & $164.6 \pm 1.1$ & $0.057 \pm 0.010$ & $-23.1 \pm 0.8$ & $72.44 \pm 1.66$ \\
\hline F14 & 0 & 0 & -1.68 & $202.6 \pm 3.5$ & $0.063 \pm 0.045$ & $-22.5 \pm 1.1$ & $82.89 \pm 6.01$ \\
\hline \multicolumn{8}{|c|}{ Central points } \\
\hline F15 & 0 & 0 & 0 & $175.4 \pm 2.1$ & $0.053 \pm 0.013$ & $-24.5 \pm 0.6$ & $74.94 \pm 1.77$ \\
\hline F16 & 0 & 0 & 0 & $176.3 \pm 1.9$ & $0.072 \pm 0.016$ & $-25.3 \pm 0.7$ & $78.14 \pm 0.49$ \\
\hline
\end{tabular}

The responses at a fixed $\mathrm{TH}$ concentration $(2.5 \mathrm{mg} / \mathrm{mL})$ are illustrated for Zav, ZP and EE (Fig. 1B-D), respectively. Results show that the highest EE was achieved at the lowest $\mathrm{pH}$, while for $\mathrm{ZP}$, the absolute high values were reached when the $\mathrm{pH}$ and surfactant were simultaneously low or high. Considering all the evaluated parameters, formulation $\mathrm{F} 4$, containing $0.25 \%$ of $\mathrm{TH}$ and $0.4 \%$ tween 20 (TW) has been optimized to carry out further experiments.

\section{Morphology and stability of TH-NP}

The morphology of TH-NP was evaluated by transmission electron microscopy (TEM) and it is shown in Fig. 2A. Moreover, TH-NP maintained their structure for 1 month at 4 and $25^{\circ} \mathrm{C}$ and additionally, for 12 months at $4{ }^{\circ} \mathrm{C}$ (Fig. 1 of SM). A small particle aggregation takes place after 12 months, which was confirmed by a slightly increased particle size, as indicated in Table 2.

This slight aggregation is also related with the decrease of ZP, since electrostatic forces between surface-charged NPs decrease when stored in aqueous media. Temperature showed to accelerate particle destabilization by decreased ZP. A slight decrease of the $\mathrm{pH}$ value was also observed, probably due to a partial hydrolysis of the polymer.

All these phenomena are in accordance with the predicted backscattering profile shown in Fig. 2 of SM, where TH-NP sedimentation was observed by the first left peak at the bottom of the vial, being reversible by agitation. Moreover, it can be observed that at $37{ }^{\circ} \mathrm{C}$ the signal greatly decreases, presenting TH-NP destabilization at higher temperatures. Additionally, EE was maintained at 4 and $25^{\circ} \mathrm{C}$ for 6 months, whereas at $37^{\circ} \mathrm{C}$, decreased by 2.5 -fold from the initial value. The parameters of all storage conditions were within stable criteria, presenting better short-term stability when stored at $4{ }^{\circ} \mathrm{C}$. Moreover, samples presented no microbial growth within storage, confirming the preservative effect of $\mathrm{TH}$.

\section{Interaction studies}

The interactions between TH and PLGA, carried out by differential scanning calorimetry (DSC) and X-ray diffraction (XRD), are shown in Fig. 2. DSC thermograms of $\mathrm{TH}$ showed an endothermic peak at $52{ }^{\circ} \mathrm{C}$, which corresponds to its melting transition (Fig. 2B). A minimal displacement of endotherm was presented by polymer alone and blank NPs (B-NP). However, TH-NP presented an onset peak displaced at $40{ }^{\circ} \mathrm{C}$, due to TH-PLGA interaction. The XRD diffractograms (Fig. 2C) show TH on its crystalline form, expressed by the sharp diffraction peaks. TH-NP could be observed as non-sharp peaks, confirming that $\mathrm{TH}$ was dispersed in the polymer matrix 

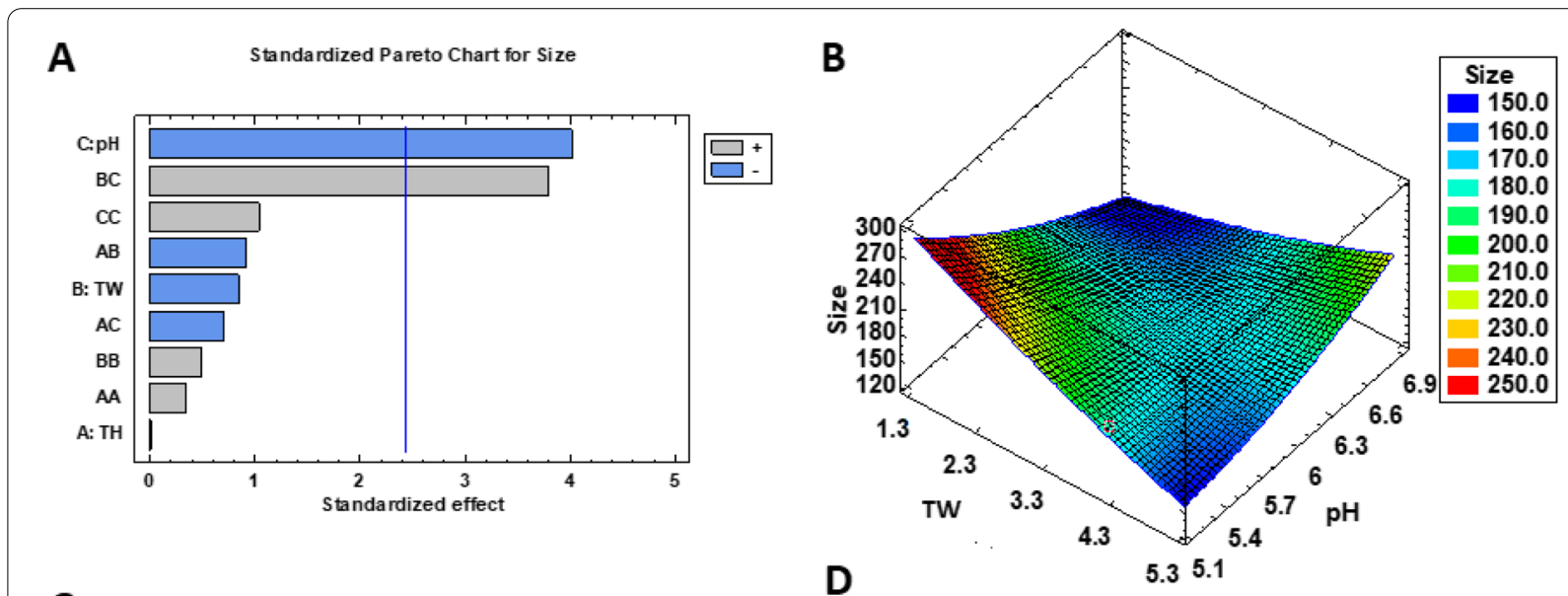

C
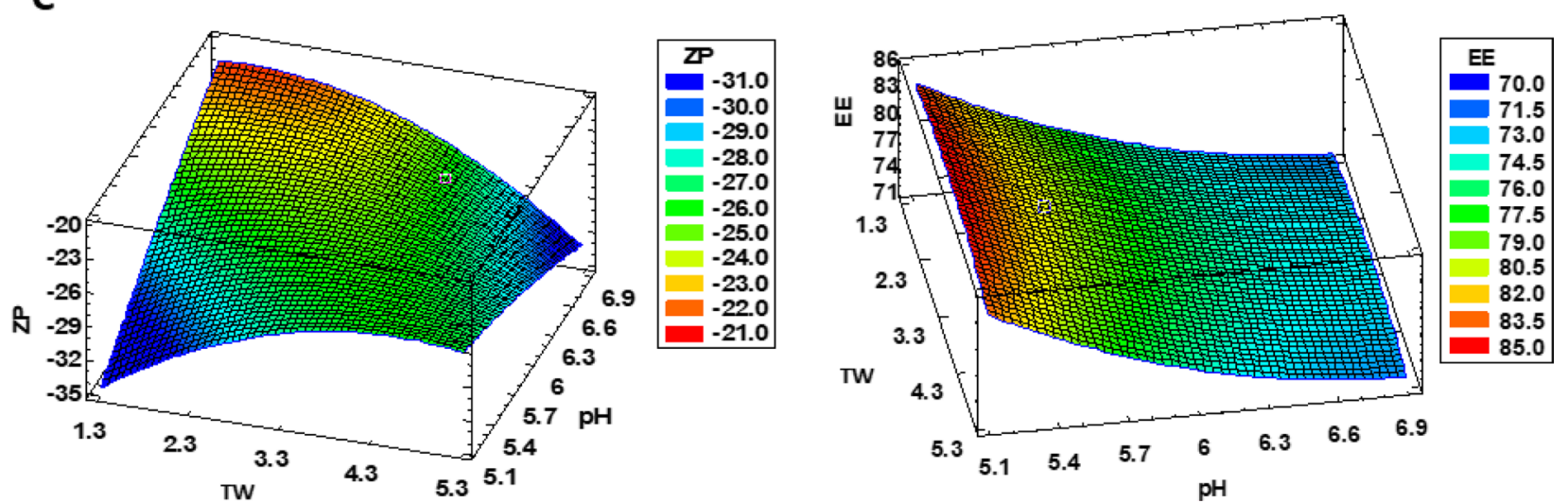

Fig. 1 Factorial design with TH-NP fixed at $2.5 \mathrm{mg} / \mathrm{mL}$ TH: A Pareto's chart for particle size (ANOVA) and surface response for B Zav particle size $(\mathrm{nm}), \mathbf{C ~ Z P}(\mathrm{mV})$ and $\mathbf{D}$ EE (\%)

in its amorphous form (molecular dispersion) and also showing a similar profile to B-NP.

\section{In vitro drug release}

The in vitro release profile of TH from TH-NP against free $\mathrm{TH}$, carried out in Franz diffusion cells, is shown in Fig. 3A. As can be observed, the release of free $\mathrm{TH}$ through the dialysis membrane was faster, while TH-NP provided a slow-rate prolonged release. Kinetic data was adjusted to Boltzmann Sigmoidal equation showing that $\mathrm{TH}$ reached $50 \%$ (V50) of total amount released within a short period of time $(1.5 \mathrm{~h})$, while TH-NP only achieved the same within $23 \mathrm{~h}$. The total amount of $\mathrm{TH}$ released in $24 \mathrm{~h}$ was $55 \%$ and $35 \%$ for $\mathrm{TH}$ and $\mathrm{TH}-\mathrm{NP}$, respectively, presenting statistically significant differences $(\mathrm{p}<0.01)$.

\section{Ex vivo skin permeation}

The ex vivo skin permeation of TH and TH-NP were performed in healthy skin and, additionally, in damaged skin, where the SC was previously scratched to mimic skin barrier disorders. The corresponding kinetics of both skin types are shown in Table 3. The permeation flux $(J)$ of TH and TH-NP were increased by 2.1- and 2.6fold, respectively, on damaged compared to healthy skin, where all samples presented significant statistical differences $(p<0.001)$ between them. In both cases, damaged and healthy skins, TH presented significantly $(\mathrm{p}<0.001)$ faster penetration rate compared to TH-NP, increased by 1.6 and 1.3 -fold, respectively. The total amount penetrated $(A p)$ was significantly higher $(\mathrm{p}<0.001)$ in damaged skin. In the other hand, the total amount retained inside the skin $(A s)$ was similar for both samples comparing healthy to damaged skins and there were significant differences $(\mathrm{p}<0.001)$ comparing TH-NP with TH.

The total amount of thymol penetrated within $24 \mathrm{~h}$ (Fig. 3B), was split into stratum corneum (SC) and deep skin (DS). The amount found in the SC was the same for $\mathrm{TH}$ on both skin types and similarly to TH-NP on damaged skin. However, for TH-NP, the retained amount was significantly higher $(\mathrm{p}<0.01)$ on normal skin, in agreement with the slow-rate penetration, presenting 
A

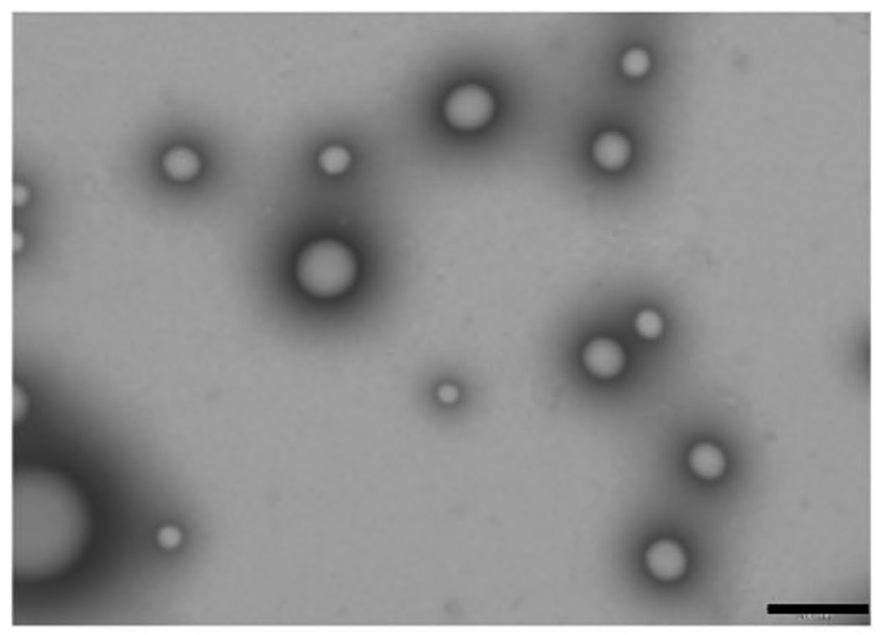

B
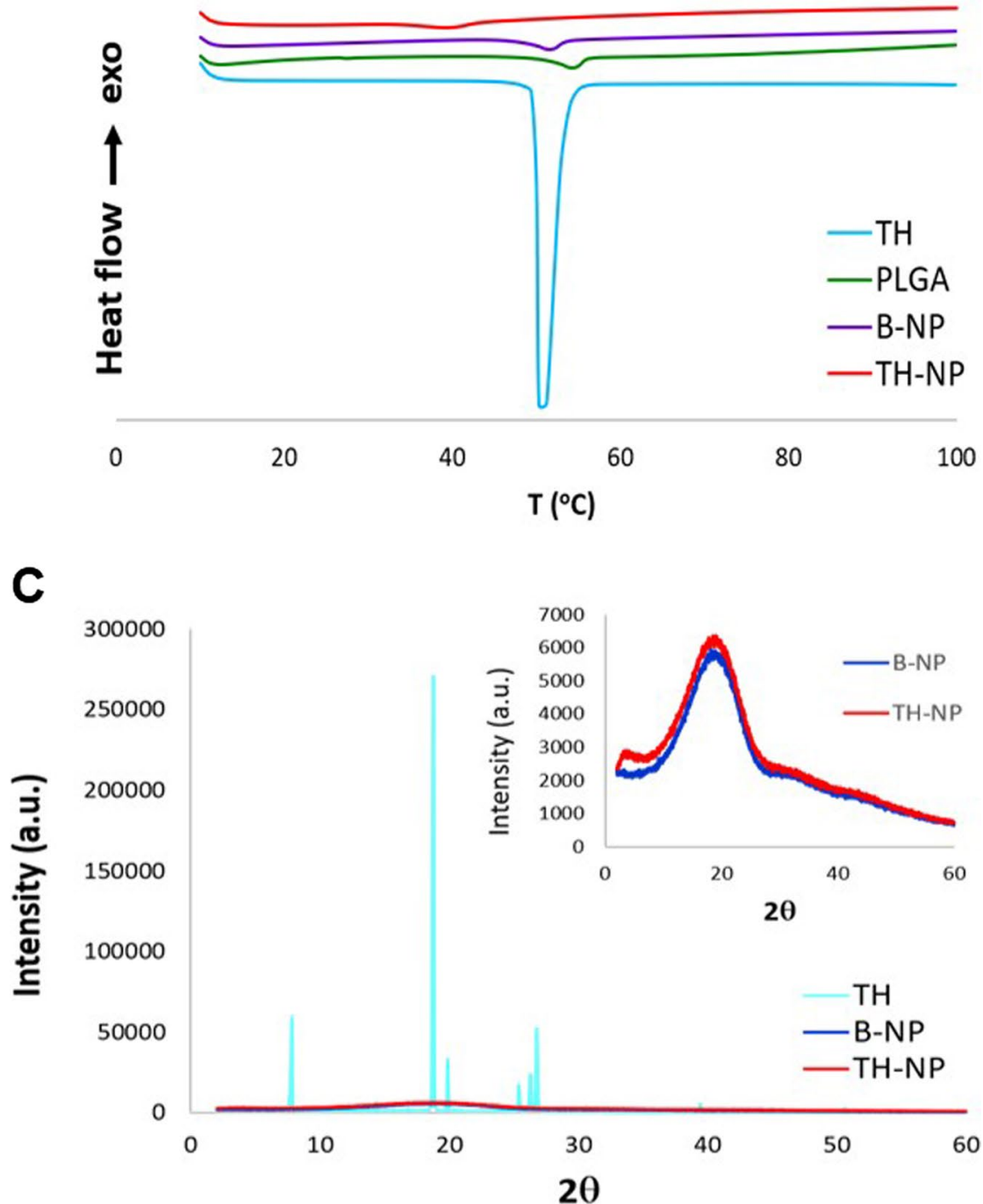

Fig. 2 A Transmission electron microscopy image of TH-NP. Scale bar: 200 nm, B DSC thermograms of TH-NP, B-NP, and compounds separately, C X-ray diffraction patterns of TH-NP, B-NP, and compounds separately 
Table 2 Physicochemical stability of TH-NP stored at different temperatures $\left(4,25\right.$ and $\left.37^{\circ} \mathrm{C}\right)$ measured at 0, 1, 3, 6 and 12 months

\begin{tabular}{|c|c|c|c|c|c|}
\hline & $t$ (months) & $\mathrm{Z}_{\mathrm{av}}(\mathrm{nm})$ & PI & $\mathrm{ZP}(\mathrm{mV})$ & $\mathrm{pH}$ \\
\hline & 0 & $158.8 \pm 1.7$ & $0.068 \pm 0.027$ & $-24.7 \pm 1.0$ & 4.20 \\
\hline \multirow[t]{4}{*}{$4^{\circ} \mathrm{C}$} & 1 & $158.6 \pm 1.8$ & $0.108 \pm 0.046$ & $-20.1 \pm 0.6$ & 4.07 \\
\hline & 3 & $159.0 \pm 2.1$ & $0.101 \pm 0.034$ & $-17.1 \pm 0.1$ & 3.90 \\
\hline & 6 & $168.6 \pm 1.7$ & $0.152 \pm 0.033$ & $-15.3 \pm 0.1$ & 3.68 \\
\hline & 12 & $204.5 \pm 1.3$ & $0.231 \pm 0.015$ & $-11.1 \pm 0.7$ & 3.61 \\
\hline \multirow[t]{2}{*}{$25^{\circ} \mathrm{C}$} & 1 & $162.3 \pm 0.4$ & $0.119 \pm 0.015$ & $-19.1 \pm 0.1$ & 3.91 \\
\hline & 3 & $182.3 \pm 1.4$ & $0.145 \pm 0.020$ & $-10.3 \pm 0.2$ & 3.64 \\
\hline \multirow[t]{2}{*}{$37^{\circ} \mathrm{C}$} & 1 & $177.4 \pm 1.2$ & $0.128 \pm 0.012$ & $-15.3 \pm 0.6$ & 3.32 \\
\hline & 3 & $216.4 \pm 2.8$ & $0.205 \pm 0.001$ & $-8.56 \pm 0.3$ & 2.95 \\
\hline
\end{tabular}

delayed entry of the particles. In the other hand, it can be observed that TH-NP presented significantly $(\mathrm{p}<0.001)$ higher amounts retained in DS on both skin types, compared to TH. Meanwhile, TH-NP on damaged skin was significantly higher than normal skin $(\mathrm{p}<0.01)$.

Ex vivo skin permeation route was studied by confocal microscopy using rhodamine-labelled TH-NP (R-TH-NP) after $24 \mathrm{~h}$ of permeation (Fig. 3C). The results obtained showed that R-TH-NP successfully penetrated inside the skin hair follicle, where acne pathogen infection and inflammation occur. The image (Fig. 3C_II) illustrates that R-TH-NP were found concentrated in the hair follicle and presented delayed entry accumulation in the SC.

\section{Cytotoxicity in $\mathrm{HaCaT}$ cells}

The cytotoxicity of TH-NP was evaluated on $\mathrm{HaCaT}$ cells, incubated for $24 \mathrm{~h}$ with concentrations up to $1 \mathrm{mg} /$ $\mathrm{mL}$ (Fig. 4A). Results showed that TH-NP was not cytotoxic at concentrations up to $50 \mu \mathrm{g} / \mathrm{mL}$, as cell viability was kept close to the untreated control cells. A $20 \%$ reduction in cell viability was observed at $100 \mu \mathrm{g} / \mathrm{mL}$ and close to $90 \%$ reduction at concentrations $\geq 250 \mu \mathrm{g} / \mathrm{mL}$. Different results were obtained with washed nanoparticles (TH-NP-w), which were not cytotoxic at $100 \mu \mathrm{g} /$ $\mathrm{mL}$ and caused only a $25 \%$ reduction in cell viability at $250 \mu \mathrm{g} / \mathrm{mL}$. Differences between TH-NP and TH-NP$\mathrm{w}$ indicate that the presence of free TW in the samples could cause toxicity to $\mathrm{HaCaT}$ cells.

\section{Cellular uptake of TH-NP}

The cellular uptake of R-TH-NP $(20 \mu \mathrm{g} / \mathrm{mL})$ was analyzed in $\mathrm{HaCaT}$ cells. At this nanoparticle concentration, cell viability was over $90 \%$. After $2 \mathrm{~h}$ incubation, fluorescence was detected by confocal microscopy in cells treated with R-TH-NP but not in untreated control cells (Fig. 4B). The cell membrane and the nucleus are represented as green and blue, respectively. In the merged images, it can be observed that the internalized nanoparticles were mainly localized in the cytoplasm.

\section{In vitro antioxidant efficacy in $\mathrm{HaCaT}$ cells}

The antioxidant activity of $\mathrm{TH}$ and $\mathrm{TH}-\mathrm{NP}$, performed in $\mathrm{HaCaT}$ cells, was successfully achieved by reducing the amount of reactive oxygen species (ROS) generated. While B-NP did not present activity, TH and TH-NP showed a $20 \%$ and $32 \%$ of ROS reduction, respectively, within $2 \mathrm{~h}$ treated with $\mathrm{H}_{2} \mathrm{O}_{2}$ (Fig. 4C). Moreover, TH-NP was statistically significant compared to $\mathrm{TH}$.

\section{In vitro antimicrobial efficacy}

The minimal inhibitory concentration (MIC) was determined for TH and TH-NP on S. epidermidis being both $512 \mu \mathrm{g} / \mathrm{mL}$. For C. acnes, TH and TH-NP displayed the same MIC and minimal bactericidal concentration (MBC) values, being $250 \mu \mathrm{g} / \mathrm{mL}$ and $400 \mu \mathrm{g} / \mathrm{mL}$, respectively. Therefore, no differences were observed in the concentrations between samples. However, there were relevant differences between different bacterial strains. In the other hand, clindamycin, a strong antibiotic commonly used to treat severe acne, presented $\mathrm{MIC}<2 \mu \mathrm{g} /$ $\mathrm{mL}$ for both microorganisms. For this reason, clindamycin is able to treat acne. However, it also affects the healthy resident bacteria of the skin.

The bacterial viability reduction, evaluated by determination of decimal reduction time (D), treated with $\mathrm{TH}$ or TH-NP in a timely manner, is illustrated in Fig. 5A. In the case of $C$. acnes, the decrease of viable bacteria correlated with the applied dose. Although the effect of $\mathrm{TH}$ and TH-NP were similar, the activity of TH-NP was slightly sustained at lower dosages. At the MIC concentrations, they present minimal reduction activity, whereas, at concentrations higher than $\mathrm{MBC}$, the reduction was boosted for all tested samples. Meanwhile, S. epidermidis presented very slow viability reduction when incubated with $\mathrm{TH}$ and $\mathrm{TH}-\mathrm{NP}$ at twice the MIC (Fig. 5B), the same highest concentration tested for $C$. acnes. It can be observed that $\mathrm{TH}$ completely reduced $S$. epidermidis viability within $8 \mathrm{~h}$, whereas TH-NP treated cultures still presented living colonies within $24 \mathrm{~h}$.

Data of decimal reduction time (D), the time taken to reduce a decimal part of the bacterial viability, is shown in Table 4. In the case of $C$. acnes, differences could be observed comparing the variable dosages applied. However, variations between $\mathrm{TH}$ and $\mathrm{TH}-\mathrm{NP}$ were not detected. In the case of S. epidermidis, TH-NP presented statistically significant differences compared to $\mathrm{TH}$. Moreover, comparing the activity between both microorganisms, at the same dosage, only TH-NP presented 


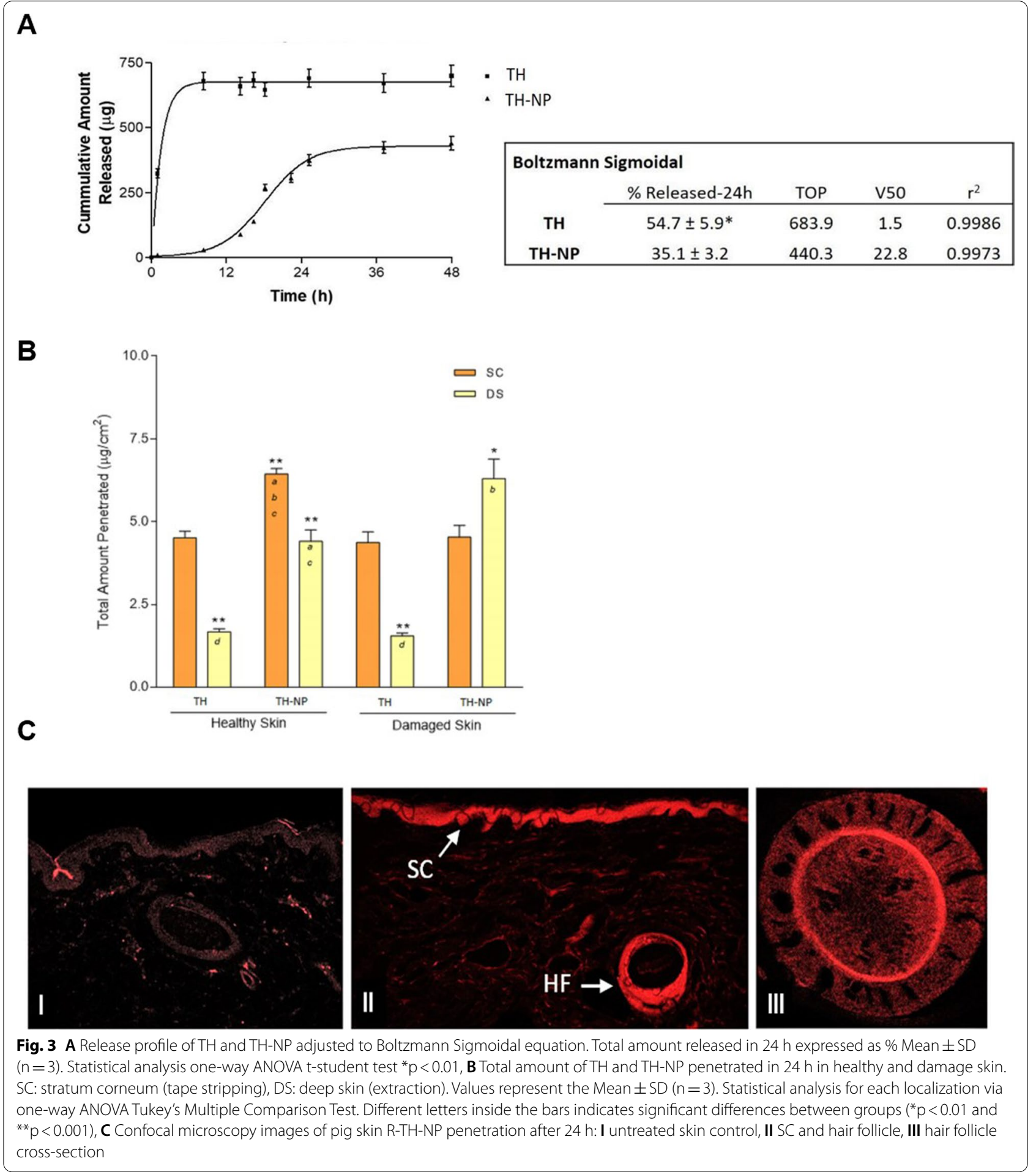

statistically significant differences for S. epidermidis against $C$. acnes.

Moreover, the structure of C. acnes (Fig. 5B), evaluated by scanning electron microscopy (SEM), presents a rod-shape and smooth membrane. Treatment with TH or
TH-NP resulted on elongated cells, thickened cell envelope, and blebs formed on the surface. 
Table 3 Ex vivo skin permeation parameters

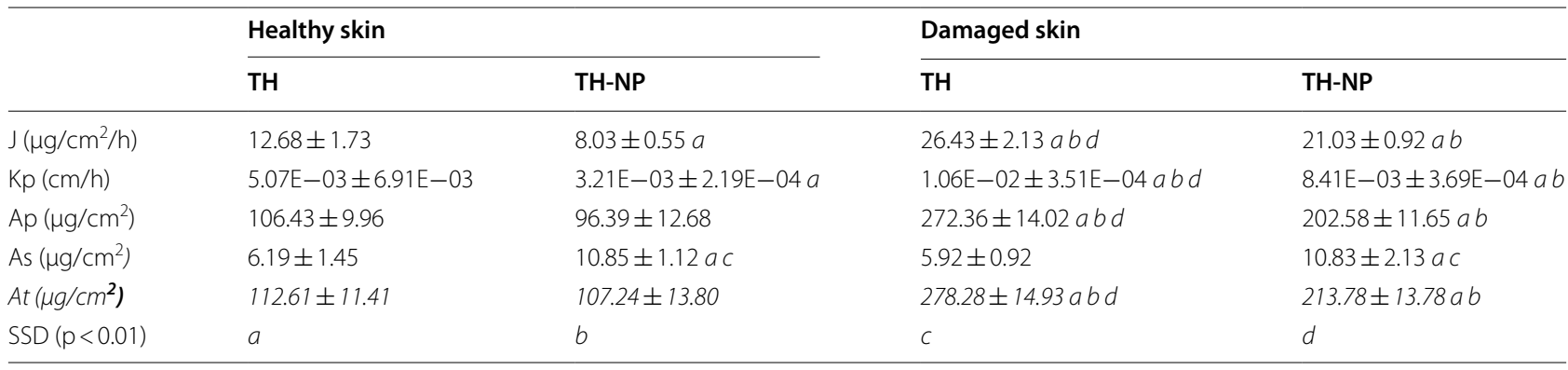

J: flux, Kp: permeability constant, Ap: total amount penetrated, As: total amount retained inside the skin, At: total amount penetrated and retained inside the skin

\section{Ex vivo antimicrobial efficacy}

The ex vivo antimicrobial efficacy of TH and TH-NP on $C$. acnes skin inoculated, as prevention or treatment for $24 \mathrm{~h}$, were successfully determined. In both studies, all samples presented significant differences against the control $(* * \mathrm{p}<0.001)$. The activity was found greater as prevention than treatment (Fig. 6A), where TH-NP presented higher activity than TH, but no statistically significant differences were observed. In the other hand, for the dose-dependent treatment (Fig. 6B), administration of a single dose showed significant differences between $\mathrm{TH}$ and TH-NP $\left({ }^{\#} \mathrm{p}<0.05\right)$.

Although TH-NP had lower effectiveness within one dose, they performed greater activity than $\mathrm{TH}$ when 2 or 3 doses were applied $(\$ p<0.001)$. Meanwhile, TH did not show statistical differences comparing the 3 dosage protocols. Moreover, the highest efficiency of the experiment was achieved by 3 doses of TH-NP.

The simulation of skin infection and treatment was carried out on ex vivo fresh human skin explants, by inoculating $C$. acnes for $16 \mathrm{~h}$, followed by $8 \mathrm{~h}$ treatment with TH or TH-NP. Morphology of C. acnes can be observed in Additional file 1: Figure S3. Moreover, Figure 6C illustrates the untreated skin and the $C$. acnes inoculated and penetrated within the skin layers. The treatment with $\mathrm{TH}$ demonstrated a fast and strong activity towards the bacteria membrane, presenting surrounding it, a great loss of intercellular material which may indicate damaged membrane. In the case of TH-NP, a slower effect with less amount of cellular leakage could be observed. The minor effects of TH-NP within $8 \mathrm{~h}$ of treatment might be related to the slow-rate release and penetration.

\section{Discussion}

In the present study, TH was successfully loaded into PLGA NP. Developed TH-NP presented suitable physicochemical parameters with excellent stability and high EE. DoE analysis showed that Pareto's diagram and surface responses indicated that only the $\mathrm{pH}$ of the aqueous phase and the ratio of $\mathrm{pH} / \mathrm{TW}$ induced statistically significant differences on $Z_{a v}$, being the effect of these variables not significant on the EE. The surfactant usually shows statistically significant influence on the EE and morphometry of polymeric NP, depending on the amount applied [27]. TW has good permeability profile and its amphiphilic properties may control the interactions between the active compound and the biopolymer carrier [31]. Interaction studies showed that encapsulated TH was present on its amorphous form and the thermal transition was affected by TH-polymer interactions [25]. Analyzing the stability of TH-NP for the first 3 months, an increase of particle size and a decrease in ZP, depending on the storage temperature, were observed. The decrease of $\mathrm{ZP}$ induced TH-NP instability in aqueous medium, due to a decrease of electrostatic forces between surfacecharged NP, generating in some cases, a slight particle aggregation. Moreover, TH-NP at high temperature,

(See figure on next page.)

Fig. 4 A Cell viability of HaCaT keratinocytes after incubation for $24 \mathrm{~h}$ with TH-NP and the washed NPs (TH-NP-w) at different concentrations. Cell viability was assayed by the MTT reduction method; $100 \%$ viability was set with the values obtained with the untreated control cells. Values represent the Mean $\pm S D(n=3)$. Statistical analysis one-way ANOVA Tukey's Multiple Comparison Test, ${ }^{*} p<0.01$ versus control and ${ }^{\$} p<0.01$ versus TH-NP-W, B Confocal microscopy analysis of HaCaT cells incubated with R-TH-NP: (I) nuclei; (II) membranes; (III) R-TH-NP; (IV) merged (I), (II), and (III), respectively; (V-VIII-h) 3D-plot of (I)-(IV), respectively, C Time course analysis of ROS production induced by $\mathrm{H}_{2} \mathrm{O}_{2}(2 \mathrm{mM})$ in $\mathrm{HaCaT}$ cells treated with TH or TH-NP. The ROS production (100\%) was set with the values obtained with cells challenged with $\mathrm{H}_{2} \mathrm{O}_{2}$ for $2 \mathrm{~h}$. Data were expressed (\%) as the Mean $\pm S D(n=8)$. Statistical analysis was performed by one-way ANOVA Tukey's Multiple Comparison Test, **p $<0.001$ versus controls at 2 h; ${ }^{\$} p<0.05$ and ${ }^{\$ \$} \mathrm{p}<0.001$ between TH and TH-NP treated cells 
A

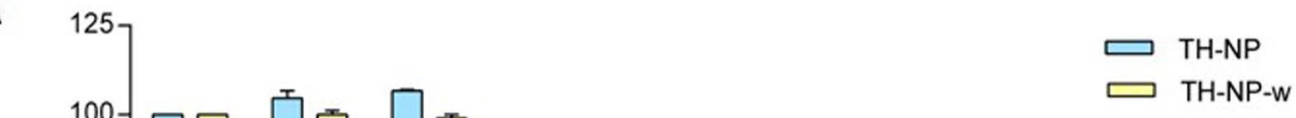

B
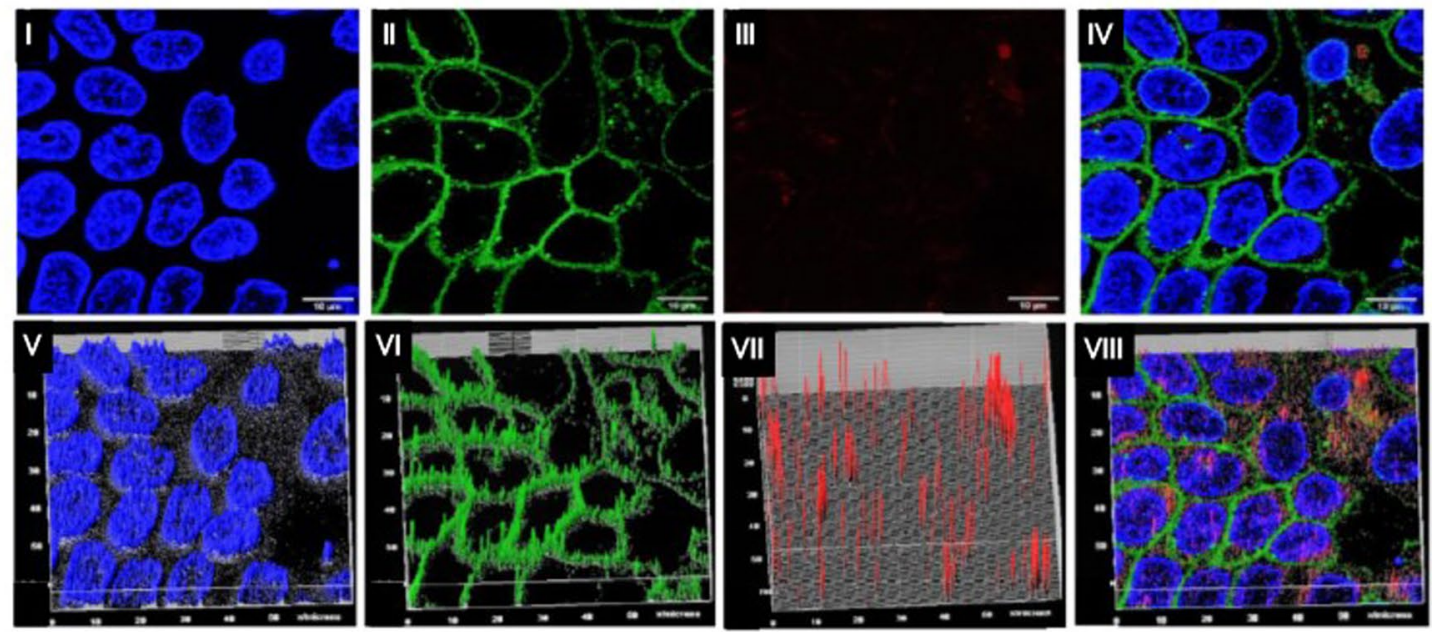

C

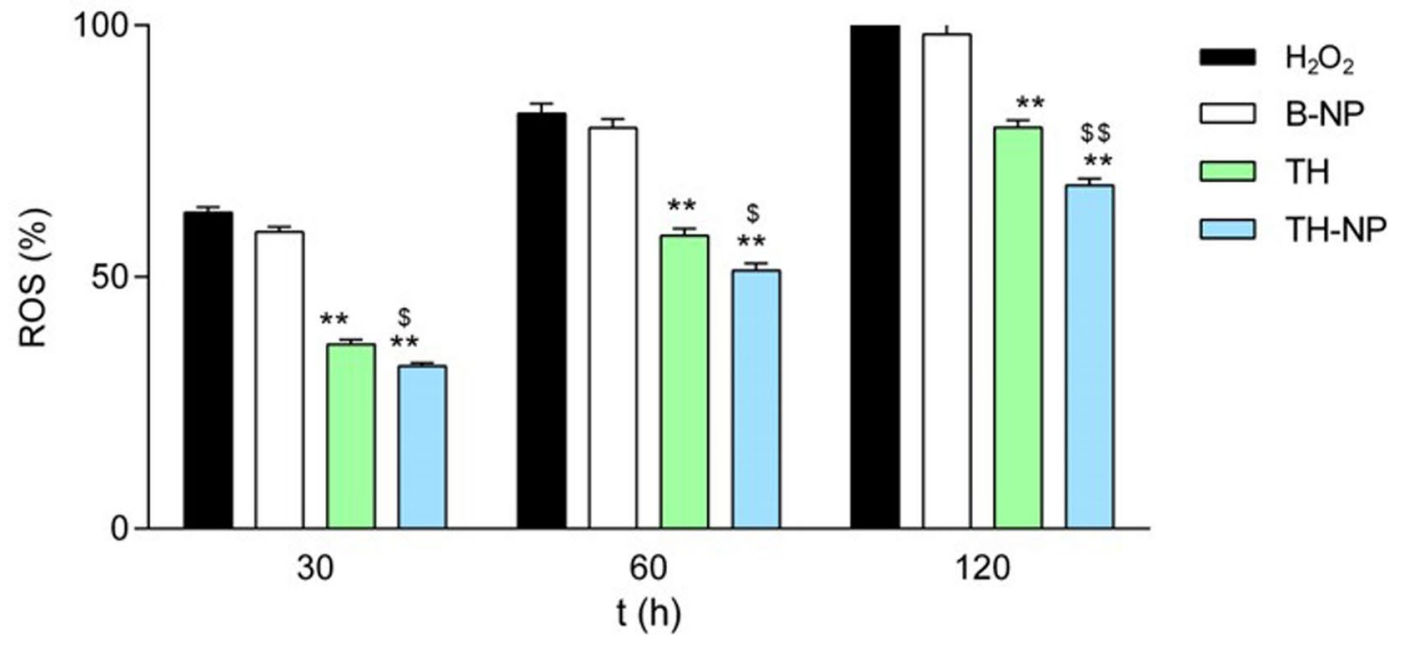

Fig. 4 (See legend on previous page.) 

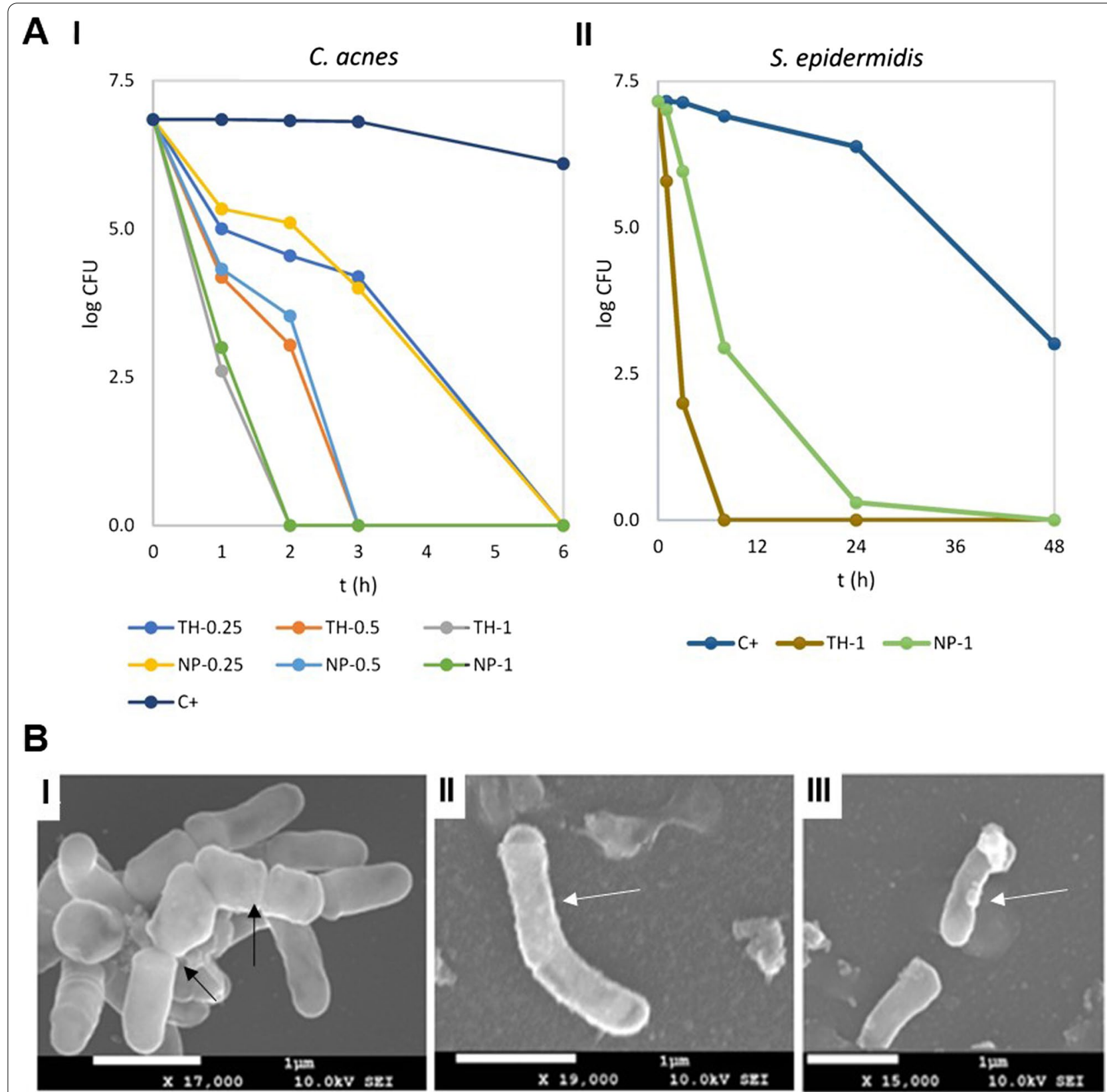

Fig. 5 A Bacterial viability reduction of (I) C. acnes $6 \mathrm{~h}$ contact with TH or TH-NP (dose dependent) at $0.25,0.5$ and $1 \mathrm{mg} / \mathrm{mL}$, (II) S. epidermidis $48 \mathrm{~h}$ contact with THF or TH-NP at $1 \mathrm{mg} / \mathrm{mL}$. Data is expressed as $\log _{10} \mathrm{CFU}$ of mean values, $\mathbf{B}$ SEM micrographs of C. acnes (I) control and treated for $1 \mathrm{~h}$ with (II) TH or (III) TH-NP. Black arrows indicate bacteria division and white arrows membrane disruption

presented sedimentation that was reversed by agitation, as also observed by other authors [32]. TH-NP stored at $4{ }^{\circ} \mathrm{C}$ have shown outstanding short-term stability in aqueous solution. However, in order to extend TH-NP stability, either incorporation in a semi-solid formulation or freeze-drying are recommended [27, 33]. In addition, it has been shown that TH-NP did not present microbial contamination along storage, confirming $\mathrm{TH}$ antimicrobial preservative activity.

Biopharmaceutical behavior of TH-NP presented a sustained in vitro release profile, while $\mathrm{TH}$ reached the steady state very fast. The ex vivo skin rate of $\mathrm{TH}$ was higher than TH-NP by 1.6 and 1.3-fold, respectively, being faster on damaged than healthy skin. As previously described [34], these results confirm that the external 


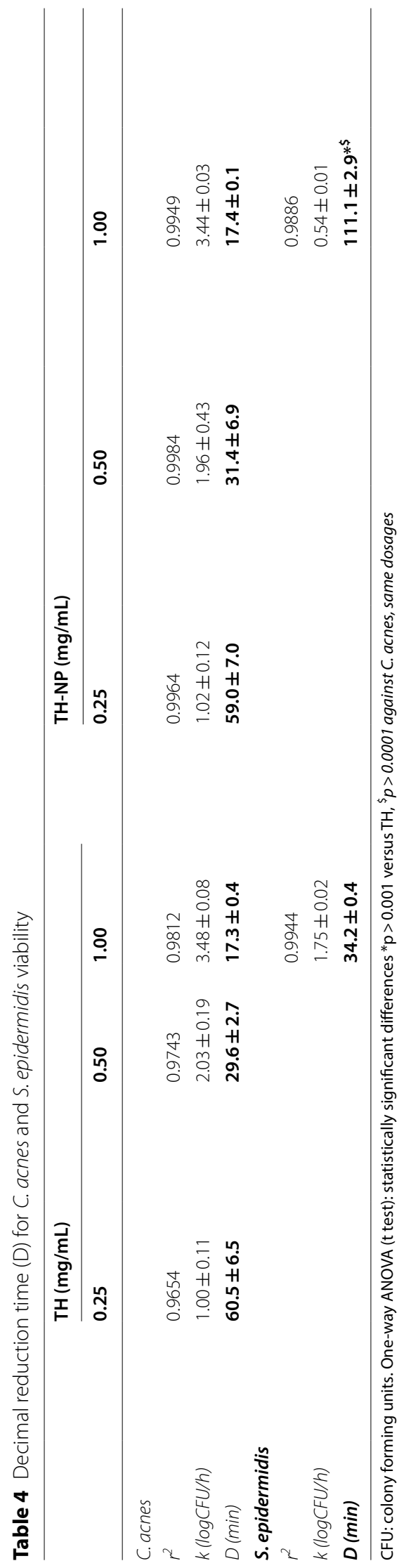




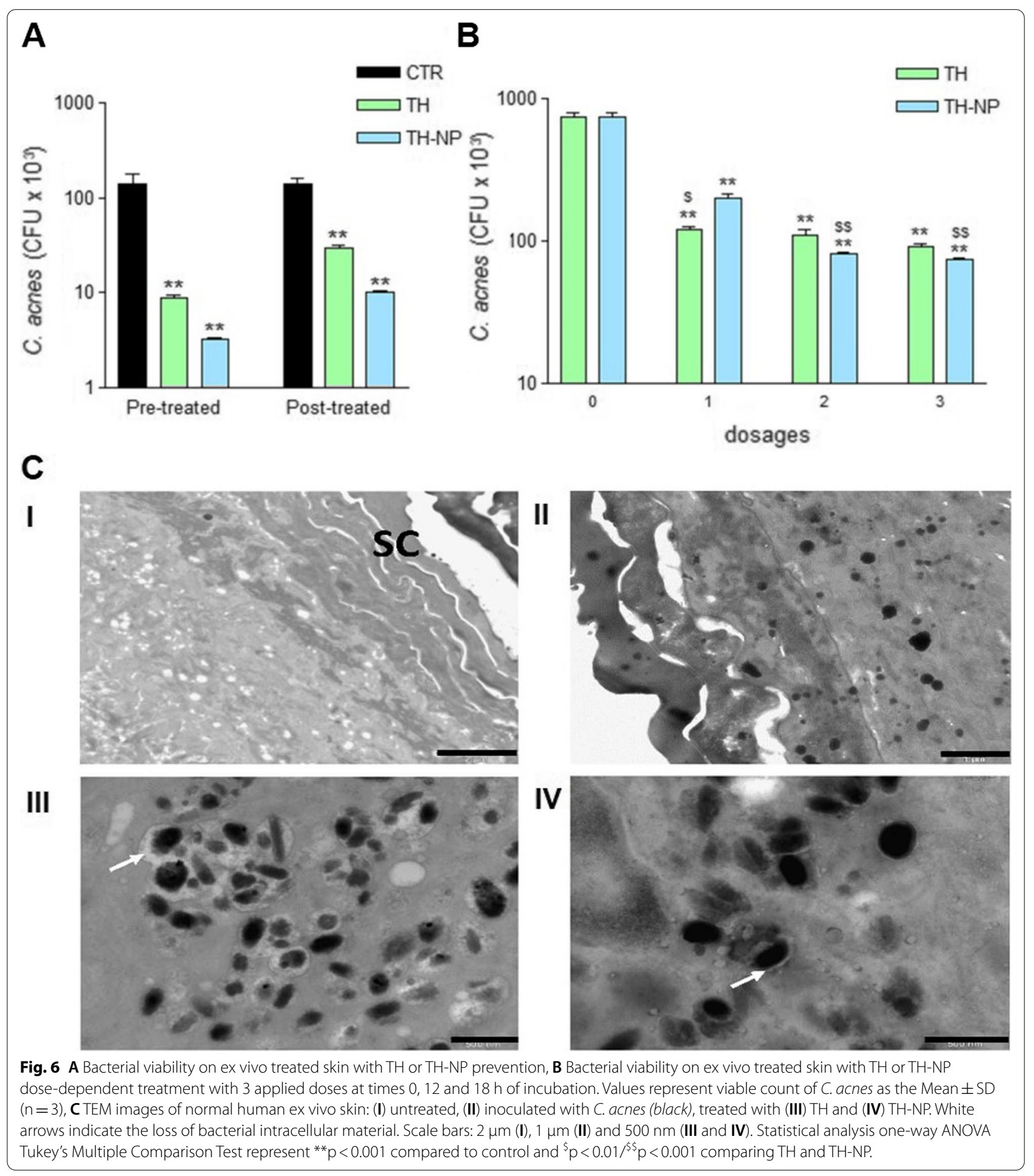

hydrophobic skin surface was altered, thus enabling substances to penetrate faster and easier through this barrier. The enhanced penetration of $\mathrm{TH}$ and TH-NP through the skin may be due to TH properties as well as the TW properties. On the one hand, $\mathrm{TH}$ is a terpene and these kind of compounds are known to be skin penetration enhancers, by impairing the lipids of the SC [35]. On the other hand, $\mathrm{TW}$, an anionic surfactant, also provide enhanced permeability through phospholipid membranes, inducing some damage to epidermal membranes 
which decrease skin resistance towards the diffusion of the active. Some authors also explained that the mechanisms of TW could be attributed to an improvement of the thermodynamic activity adsorption and fusion due to micellar complexation, or decreasing the SC hindrance or modification of its intracellular lipid barriers [36]. The amount of $\mathrm{TH}$ retained inside the skin was higher for TH-NP in both (healthy and damaged) skin types. The only difference between healthy and damaged skins was the highest amount in the SC and DS, respectively. The lesser amount of free $\mathrm{TH}$ against TH-NP retained inside the skin was probably due to its fast-rate penetration. In agreement with TH-NP slow-rate penetration, confocal microscopy study confirmed that TH-NP presented delayed entry, accumulating into the layers of the SC. This means that when the $\mathrm{SC}$ was disrupted, the flux of NPs penetration improved, and therefore, the amount inside the deeper layers of the epidermis and dermis increased. Interestingly, TH-NP skin penetration route was through the hair follicle, exactly where acne occurs. According to previous authors [37], the physicochemical properties of the active compound as well as the barrier properties of the hair follicles define the penetration route (intrafollicular or transfollicular). Polymeric NPs preferentially accumulate in the follicular entry, in a time dependent manner, where the skin penetration through the hair follicle is size dependent [8]. In this way, particles with average diameter of $200 \mathrm{~nm}$ are likely to penetrate faster than micro-sized particles or free molecules. Therefore, the smaller the particle size, the higher would be the accumulation into the hair follicle, and thus achieving lower permeability rates $[8,37]$. Studies carried out by Yukuyama et al. [38], indicated that NP stored in the hair follicle will be cleared by hair growth or sebum production. Zhu et al.[39], developed PLGA TH microparticles as antimicrobial agents for food preservative application, containing particle size ranging for 20 to $70 \mu \mathrm{m}$. Due to the fact of the particle size selectivity for follicle entry, our developed TH-NP would be more efficient for penetrating the hair follicle to treat acne. Furthermore, other authors stated that the reservoir of the hair follicle could store actives 10 times longer than the reservoir of the $\mathrm{SC}$, and also, that hair follicle under movement (in vivo) would improve NP penetration [37, 38]. Recent studies confirmed that diffusion of polymeric NPs only crossed the SC reaching the viable epidermis only after needle puncture [37]. This could be also observed, by confocal microscopy in healthy skin, where TH-NP were not found beyond the SC, unless inside the hair follicle. For all these reasons, TH-NP are more efficient for acne treatment due to the prolonged penetration and release inside the hair follicle.
In the $\mathrm{HaCaT}$ cell line, TH-NP at low concentrations did not alter cell viability, presenting no cytotoxicity. The cellular uptake images showed most of the NPs in the cytosol but also some particles reached the nucleus within only $2 \mathrm{~h}$. This would enable TH-NP to perform its antioxidant activity inside the cells to improve the skin healing process on acne lesions [20]. This activity was confirmed by reducing the ROS generated, since TH-NP improved significantly compared to TH. Moreover, prolonged release of $\mathrm{TH}$ as well as increased stability of TH-NP may also favor enhanced antioxidant activity.

The antimicrobial activity of TH and TH-NP against $C$. acnes was similar and successfully demonstrated in vitro and ex vivo. The in vitro activity increased with high concentrations of TH-NP, and they presented the decimal reduction of bacterial viability within 60,30 and $17 \mathrm{~min}$, for MIC, $2 \times$ MIC and $4 \times$ MIC, respectively, confirming dose-dependent activity. Additionally, the concentrations used above $\mathrm{MBC}$ completely reduced all CFU very fast. For the ex vivo experiments, simulating an acne infection inside the skin explant, samples resulted more efficient for prevention than treatment, despite, no significant differences between samples could be observed. This can be explained by the fact that part of the amount of the formulations applied were retained on the SC, and therefore, products had a direct contact with $C$. acnes when this was inoculated onto the skin. Meanwhile TH penetrates faster throughout the skin, providing only an immediate effect. For TH-NP, the effectiveness was higher when multiple dosages were applied onto the skin providing a slightly sustained effect. These results are in accordance with those observed in the biopharmaceutical studies. The same behavior was observed by electron microscopy in the ex vivo images, where the effect of $\mathrm{TH}$ on the bacterial membrane was found stronger than TH-NP, for $8 \mathrm{~h}$ contact inside the skin. For this reason, it could predictably act in the same way on skin microbiota and therefore, TH-NP would constitute a less aggressive and more efficient system for such treatment. The in vitro SEM images showed modified cells, with greater wall thickness and the development of blebs [40]. This observation agrees with the previously mentioned mechanism of antimicrobial activity, by triggering loss of intercellular nutrients.

Concerning S. epidermidis, a more resistant type of microorganism, it presented very slow viability reduction in contact with $\mathrm{TH}$ and TH-NP, compared to $C$. acnes, even tested at the highest concentration. Growth was abolished within $8 \mathrm{~h}$ for $\mathrm{TH}$, while for TH-NP this effect was observed over $24 \mathrm{~h}$. Therefore, if these NP were administered in vivo for acne skin treatment, at the same concentrations, it would be less effective towards the entire skin microbiota, being at the same time a 
strong bactericidal against $C$. acnes. This favors the desirable microbiota-friendly activity, where the antimicrobial ingredient will not alter the good functionality of the healthy skin, acting efficiently against $C$. acnes and only mediating S. epidermidis proliferation. Another proof of concept was previously stated by other authors [41] providing evidence that microbiota shifts notably during puberty, increasing predominance of Cutibacterium species and decreasing abundance of Staphylococcus species. Meanwhile, in adulthood it remains unstable due to constant external environmental changes, suggesting mutual beneficial microbiome-host interactions. As a complement, the MICs showed that the concentration needed as bactericidal against $C$. acnes was lower than the minimal concentration needed to inhibit $S$. epidermidis growth. This means that for in vivo conditions, the desirable effect for acne treatment would maintain the skin balanced. In the case of clindamycin, the MIC for C. acnes and S. epidermidis was confirmed to be strongly efficient at a very low dose. This powerful activity is the main challenge with this type of drug, since it completely abolishes all the microbial content of the skin, therefore, treating it by unbalancing the healthy conditions for the microbiota, thus, leading to microbial resistance. For this reason, in this study we managed to confirm an effective activity of a natural active, at higher concentration, but that can maintain the microbiota function to rebalance the skin conditions, maintaining it healthy upon the treatment.

From another point of view, since the route of penetration of polymeric TH-NP into the skin was through the hair follicle, the observed activity will be performed directly on the acne lesion. Therefore, TH-NP perform a protective effect on the healthy skin microbiota, along with extending the retention and release of $\mathrm{TH}$, directly to the site of the infection with prolonged activity. Moreover, the sebum content on the hair follicles could facilitate absorption and release of TH from TH-NP by hydrophobic interactions. Nevertheless, since PLGA skin metabolism occurs by biodegradation into its monomers (lactic acid and glycolic acid), these compounds may help to modulate the skin $\mathrm{pH}$, which would contribute to the sebum control.

\section{Conclusions}

TH was successfully encapsulated into PLGA NPs with particle size below $200 \mathrm{~nm}$ and high EE with suitable stability. Moreover, TH-NP solution did not present microbial growth under a storage period of 12 months, due to antimicrobial properties of $\mathrm{TH}$. Therefore, they can act as natural preservative system. TH-NP presented a sustained release and slow-rate penetration on skin, through the hair follicle, with higher amounts retained inside the skin, compared to TH free. Moreover, TH-NP showed outstanding antimicrobial activity in vitro and ex vivo against $C$. acnes, with minor effects towards $S$. epidermidis, which promises to be a great microbiotafriendly candidate for acne treatment. Additionally, TH-NP adhered into the SC layers would provide good protection on the acne lesions against external microbial aggressors. Moreover, the cellular uptake of TH-NP has also improved the antioxidant activity in keratinocyte cells, which would be promising on cell regeneration on the healing process of the acne lesion. Therefore, TH loaded nanostructured system has been successfully developed and physicochemically characterized demonstrating excellent properties for acne topical treatment.

\section{Methods \\ Materials}

PLGA Resomer ${ }^{\circledR}$ RG 504H (consisting of a carboxylic terminal group, molecular weight $38,000-54,000 \mathrm{Da}$ and molar ratio lactide:glycolide 50:50) was purchased from Boehringer Ingelheim (Ingelheim, Germany). Thymol (TH), Tween 20 (TW) and acetone were purchased from Sigma-Aldrich (Spain). Milli-Q water was obtained from a double distilled Millipore system. All chemicals and reagents used were analytical grade (HPLC).

\section{Preparation of TH-NP}

TH-NP containing a matrix structure (nanospheres) were obtained by solvent displacement evaporation, described by Fessi et al. [42]. Briefly, an aqueous phase containing TW and an organic phase were prepared. The organic phase was made by dissolving PLGA and TH in acetone, and it was added dropwise into the aqueous phase under continuous stirring. Finally, in order to evaporate the organic solvent, a rotatory evaporator (Buchi, Switzerland) was used at $30{ }^{\circ} \mathrm{C}$ under constant pressure, obtaining TH-NP dispersed in water [43-45].

\section{Optimization of TH-NP}

TH-NP were optimized using the design of experiments approach (DoE). A full factorial central design of five levels and three factors was applied in order to reduce the number of experiments [46]. This experimental design consisted of 16 formulations with variable factorial points $(-1 /+1)$, axial points $(-1.68 /+1.68)$ and central points $(0)$, each involving 8, 6 and 2 formulations, respectively. The concentration of active (TH), surfactant (TW) and the $\mathrm{pH}$ of the aqueous phase were selected as the independent variables (Table 5). PLGA was fixed to $9 \mathrm{mg} / \mathrm{mL}$ for the entire experiment. The effect of the independent on the dependent variables (morphology, z-potential and encapsulation efficiency) has been analyzed [47]. 
Table 5 Factors and levels of DoE independent variables

\begin{tabular}{llllll}
\hline Factors & Levels & & & & \\
\cline { 2 - 6 } & $\mathbf{- 1 . 6 8}$ & $\mathbf{- 1}$ & $\mathbf{0}$ & $\mathbf{1}$ & $\mathbf{1 . 6 8}$ \\
\hline $\mathrm{TH}(\mathrm{mg} / \mathrm{mL})$ & 1.16 & 1.5 & 2.0 & 2.5 & 2.84 \\
$\mathrm{TW}(\mathrm{mg} / \mathrm{mL})$ & 1.32 & 2.0 & 3.0 & 4.0 & 4.68 \\
$\mathrm{pH}$ & 4.32 & 5.5 & 6.0 & 6.5 & 7.68 \\
\hline
\end{tabular}

\section{Physicochemical characterization of TH-NP}

$\mathrm{Z}_{a v}$ and PI were determined by photon correlation spectroscopy, using a ZetaSizer Nano ZS (Malvern Instruments; Malvern, UK). The surface charge, measured as ZP, was determined by electrophoretic mobility using the same instrument. The morphology of the particles was accessed by TEM (transmission electron microscopy, JEOL JEM1010, Tokyo, Japan), using Megaview III (Soft Imaging Systems, GmbH, Münster, Germany). The negative staining was carried out with $2 \%$ uranyl acetate.

Quantitative analysis was performed by reverse-phase high-performance liquid chromatography (HPLC) by a modification of the method described previously [48]. Studies were carried out in Acquity Waters System with UV detector, using a Kromasil $^{\circledR}$ column (C18, $5 \mu \mathrm{m}, 150 \times 4.6 \mathrm{~mm})$. The mobile phase consisted of acetonitrile:water under gradient conditions of 30:70/58:42/30:70 during $20 \mathrm{~min}$. TH was determined at wavelength of $275 \mathrm{~nm}$.

The encapsulation of TH was measured indirectly by quantification of unloaded amount. Samples were diluted 1:10 in Milli-Q water:ethanol (90:10) and centrifuged (Centrifuge 5415C, Geratebau Eppendorf $\mathrm{GmbH}$, Engelsdorf, Germany) for $10 \mathrm{~min}$ at $14,000 \mathrm{rpm}$, using Millipore filter device (Amicon ${ }^{\circledR}$ Ultra, $0.5 \mathrm{~mL} 100 \mathrm{~K}$, Merck Millipore Ltd., Carrigtwohill Co. Cork IRL). The filtered fractions were quantified by HPLC, and the EE was determined by Eq. (1):

$$
\mathrm{EE}=\frac{\mathrm{Ci}-\mathrm{Cs}}{\mathrm{Ci}} \cdot 100
$$

where $C i$ is the initial concentration of the active and $C s$ is the concentration of the unloaded amount found in the filtered fraction.

\section{Interaction studies}

Interaction studied were carried out by previous ultracentrifugation of the samples at 15,000 rpm during $30 \mathrm{~min}$ of TH-NPs (Beckmann-Coulter ultracentrifuge). The possible interactions between TH and PLGA were assessed by differential scanning calorimetry (DSC). Thermograms were obtained on a DSC823e System (Mettler-Toledo,
Barcelona, Spain). A pan with indium (purity $\geq 99.95 \%$; Fluka, Switzerland) was used to check the calibration of the calorimetric system and an empty pan was used as a reference [25]. Samples were heated from $10{ }^{\circ} \mathrm{C}$ to $100{ }^{\circ} \mathrm{C}$ at $5{ }^{\circ} \mathrm{C} / \mathrm{min}$ under a nitrogen atmosphere. Data were evaluated from the peak areas with Mettler STARe V 9.01 DB software (Mettler-Toledo). The physical state (amorphous or crystalline) of TH and TH-NP was analyzed by X-ray diffraction (XRD). Samples were sandwiched between $3.6 \mu \mathrm{m}$ films of polyester and exposed to $\mathrm{Cu} K \alpha$ radiation $(\lambda=1.5418 \AA)$ with work power $(45 \mathrm{kV}$, $40 \mathrm{~mA}$ ). Diffractograms were recorded on a PANalytical X'Pert PRO MPD $\theta / \theta$, powder diffractometer of $240 \mathrm{~mm}$ of radius, using PIXcel detector (active length $=3.347^{\circ}$ ). The measure time was defined $200 \mathrm{~s}$ per step, $2 \theta / \theta$ scans from 2 to $60^{\circ} 2 \theta$ with a step size of $0.026^{\circ} 2 \theta$ [49].

\section{Stability of TH-NP}

The physicochemical stability of the optimized formulation was followed during storage at different conditions: 25 and $37{ }^{\circ} \mathrm{C}$ for 3 months and $4{ }^{\circ} \mathrm{C}$ for 12 months. The stability was studied by measuring backscattering of near-infrared pulsed light $(\lambda=880 \mathrm{~nm})$, bottom-to-top of the turbiscan cell containing TH-NP, using optical analyzer Turbiscan ${ }^{\circledR}$ Lab expert (Formulaction, L'Union, France), to predict the behavior of the NPs in solution. Additionally, measurements of $\mathrm{Z}_{\mathrm{av}}, \mathrm{PI}, \mathrm{ZP}$ and TEM images were also monitored at selected times. The EE stability was also measured at 6 months of storage.

To analyze the microbial preservative activity of $\mathrm{TH}$ during storage, samples stored for 6 months at room temperature and 12 months at $4{ }^{\circ} \mathrm{C}$ where used. For direct measurement, $0.1 \mathrm{~mL}$ of each sample was transferred into the plates or, additionally, samples where diluted 1:10 in neutralizing solution (Berens Cosmetic Diluent, Scharlab, UK), then $1 \mathrm{~mL}$ was transferred into the plates. The total viable count was carried out by inclusion on TSA (Tryptone Soy Agar, Oxoid, UK) for bacteria or Sabouraud Dextrose Agar (Oxoid, UK) for fungi and yeasts. Plates were incubated at $35 \pm 2{ }^{\circ} \mathrm{C}$ for 3 days or at $28 \pm 2{ }^{\circ} \mathrm{C}$ for 7 days, respectively. This methodology was designed based on specifications of the European Pharmacopeia monographs (2.6.12. Microbiological examination of non-sterile products: total viable aerobic count).

\section{In vitro release}

The in vitro release of $\mathrm{TH}$ from $\mathrm{TH}-\mathrm{NP}$ against free $\mathrm{TH}$ was carried out using vertical diffusion Franz cells (FDC400 , Vidra-Foc, Barcelona, Spain) with a thermal bath set to $32{ }^{\circ} \mathrm{C}$, to mimic skin in vivo conditions, under constant stirring. For this study, methylcellulose membranes (Dialysis Tubing - ViskingCode DTV12000.03.000, Size 3, Inf 
Day 20/32" -15.9 mm, MWCO-12-14.000 Da, Liverpool Road, London, UK) were placed between donor/receptor compartments $\left(2.54 \mathrm{~cm}^{2}\right)$. Samples of TH or TH-NP were added to the donor phase $(0.5 \mathrm{~mL})$ and the receptor phase was filled with Transcutol $\mathrm{P}^{\circledR}$ :water (50:50), maintaining sink conditions. Aliquots of $300 \mu \mathrm{L}$ were collected at selected times, replaced with the same amount of receptor medium [33]. Data were analyzed by HPLC and processed with the Boltzmann Sigmoidal mathematical model, Eq. (2), using GraphPad ${ }^{\circledR}$.

$$
Y=\frac{\text { Bottom }+(\text { Top }- \text { Bottom })}{\left(1+\exp \left(\frac{\text { (V50-X) }}{\text { Slope }}\right)\right.}
$$

\section{Ex vivo skin permeation}

Ex vivo human skin permeation was carried out by vertical diffusion Franz Cells, using the same methodology as described above. Human skin was obtained from abdominal plastic surgery (Hospital de Barcelona, SCIAS, Barcelona, Spain), following a protocol approved by the Bioethics Committee of the Barcelona-SCIAS Hospital. Skin samples $\left(2.54 \mathrm{~cm}^{2}, 0.4 \mathrm{~mm}\right.$ thick) were clamped into the Franz cells with the SC facing up [50]. Previously, some of the skin samples were scratched with sandpaper to mimic damaged skin SC. The donor compartment was filled $(0.5 \mathrm{~mL})$ with TH or TH-NP $(0.25 \%)$. Data were analyzed by HPLC and processed using GraphPad ${ }^{\circledR}$. The skin permeation parameters were calculated by Eq. (3):

$$
J=K p \cdot C_{0}
$$

where $J$ is the flux, $K p$ is the permeability coefficient and $C_{0}$ is the initial concentration of the active [51].

The amount retained inside the skin was assessed by tape striping and skin extraction techniques. Firstly, skin samples were washed with sodium lauryl sulphate $(0.02 \%)$ and rinsed with distilled water, dried, cut, and weighted. For determination of the amount retained in the SC, tape stripping assay was developed based on previous authors with minimal modifications [52]. The first layers of the skin were removed by 7 strips of the same region of the SC using a transparent label dressing ( $3 \mathrm{M}$ Tegaderm $^{\circledR}, 6 \times 7 \mathrm{~cm}, 10 \mathrm{u}$, Spain, S.A.). The strips were added into $4 \mathrm{~mL}$ of ethanol and placed into an ultrasonic bath (JP, Selecta) for 20 min for compound extraction. For determination of the total amount retained inside the deeper layers, the rest of the skin was perforated, added into $2 \mathrm{~mL}$ of ethanol:water (50:50) and then kept in the ultrasonic bath for $20 \mathrm{~min}$ [51]. The amount of thymol extracted was determined by HPLC and calculated using the recovery factor previously obtained.

To determine the permeation route of TH-NP, vertical diffusion Franz cells were used as described before.
Ex vivo pig skin penetration was obtained from the animal house (Bellvitge, University of Barcelona), used in accordance with the protocol approved by the Ethics Committee of the University of Barcelona. For this study, rhodamine-labelled PLGA (R-PLGA) was synthesized as previously described [43]. R-PLGA was used at $0.01 \%$ into TH-NP, added in the organic phase with PLGA. R-TH-NP were applied onto the ex vivo pig skin $0.64 \mathrm{~cm}^{2}$ (donor compartment) and allowed penetration for $24 \mathrm{~h}$. Skin samples were washed, fixed in PBS containing $4 \%$ paraformaldehyde (PFA) for $4 \mathrm{~h}$, followed by cryoprotection into PBS with $30 \%$ sucrose for $24 \mathrm{~h}$, snap-frozen in isopentane at $-50{ }^{\circ} \mathrm{C}$, then kept overnight at $-80{ }^{\circ} \mathrm{C}$. Samples were mounted in O.C.T. ${ }^{\circledR}$ Compound (Tissue-Tek ${ }^{\circledR}$, Sakura) and sliced with cryostat microtome (LEICA CM3050 S) at $-20{ }^{\circ} \mathrm{C}$ onto glass-slides Superfrost ${ }^{\circledR}$ Plus (Menzel-Glaser, Thermo Scientific, USA), covered with Fluoromount $G^{\circledR}$ (Invitrogen, Thermo Fisher Scientific, USA). Samples were visualized by confocal laser scanning microscopy (Zeiss LSM 880), using objective lens $10 \times 0.45$. Images were acquired using Zen Black 2.3 software performing z-stack sections and thus processed with ImageJ software.

\section{Cytotoxicity studies in HaCaT cells}

Human keratinocytes $(\mathrm{HaCaT})$ cells were cultured in high glucose DMEM (Dulbecco's Modified Eagle's Medium (Thermofisher), supplemented with $10 \%$ fetal bovine serum (FBS), $2 \mathrm{mM}$ L-glutamine, 100 units $/ \mathrm{mL}$ penicillin $\mathrm{G}$ and $100 \mu \mathrm{g} / \mathrm{mL}$ streptomycin. Cells were incubated at $37{ }^{\circ} \mathrm{C}$ and $5 \% \mathrm{CO}_{2}$ and experiments were performed when cells reached $80-90 \%$ of confluence.

Cytotoxicity of TH-NP was determined by MTT (3-(4,5-Dimethylthiazol-2-yl)-2,5-diphenyl tetrazolium bromide) assay, by reduction of tetrazolium salt by intracellular dehydrogenases of viable living cells. TH-NP were tested at concentrations up to $1 \mathrm{mg} / \mathrm{mL}$. The assay was also performed with TH-NP previously washed thrice (TH-NP-w) to remove excess of free TW (centrifugation at $14,000 \mathrm{rpm}$ for $15 \mathrm{~min}$ ). Briefly, $\mathrm{HaCaT}$ cells were seeded in 96-well plates with $100 \mu \mathrm{L}$ of culture medium (DMEM) at a density of $2 \times 10^{5}$ cells/well, adjusted in automated cell counter (Countess, Invitrogen, Thermofisher). Cells were incubated with samples for $24 \mathrm{~h}$. Then, the medium was removed and MTT (Sigma-Aldrich Chemical Co, St. Louis, MO, USA) was added at $0.25 \%$ in PBS. After $2 \mathrm{~h}$ incubation, the medium was replaced by $100 \mu \mathrm{L}$ DMSO (99\% dimethyl sulfoxide, Sigma-Aldrich) [53]. Cell viability was then measured at wavelength of $570 \mathrm{~nm}$ in a Modulus ${ }^{\circledR}$ Microplate Photometer (Turner BioSystems Inc., Sunnyvale, CA, USA). Results were expressed as percentage of cell survival relative to untreated cells. 


\section{Cellular uptake of TH-NP}

Cellular uptake of TH-NPs was assayed in HaCaT cells seeded in an 8 -well $\mu$-slide $\left(\right.$ Ibidi $^{\circledR}$ ) following the same methodology as described before. Cells were incubated with or without R-TH-NP for $2 \mathrm{~h}$ at the indicated concentration, using FBS/phenol red free medium. Cell membranes were stained with wheat germ agglutinin (WGA) Alexa-488 (Molecular Probes) at $1 \mu \mathrm{g} / \mathrm{mL}$ for 15 min followed by fixation with paraformaldehyde $3 \%$ for $25 \mathrm{~min}$. Cell nuclei were stained with $4^{\prime}, 6$-diamidino-2-phenylindole (DAPI, Sigma Aldrich, Spain) at $0.5 \mu \mathrm{g} / \mathrm{mL}$ for $15 \mathrm{~min}$. Internalization of NPs in $\mathrm{HaCaT}$ cells was assessed by confocal microscopy (Leica TCS SPII), $63 \times$ oil immersion objective lens [43]. Images were processed using Fiji image software.

\section{In vitro antioxidant efficacy in $\mathrm{HaCaT}$ cells}

The antioxidant activity of $\mathrm{TH}, \mathrm{TH}-\mathrm{NP}$, and B-NP (blank NPs) was assayed in $\mathrm{HaCaT}$ cells by quantification of ROS using the fluorogenic probe H2DCFDA. Cells were seeded in 96-well plates at $2 \times 10^{5}$ cells/well $(100 \mu \mathrm{L})$ for $72 \mathrm{~h}$. Cells were loaded with the fluorogenic dye $\mathrm{H}_{2}$ DCFDA (2',7'-dichlorodihydrofluorescein diacetate) at $25 \mu \mathrm{M}$ diluted in DMEM medium absent of phenol red and FBS, for $45 \mathrm{~min}$ in the dark. This fluorogenic dye passively diffuses into the cells, being deacetylated by intracellular esterase and emits fluorescence upon oxidation by reactive oxygen species (ROS) [54]. Then, cells were washed with PBS and incubated for $2 \mathrm{~h}$ with TH, TH-NP or B-NP. After this period, 10 $\mu \mathrm{L}$ of $\mathrm{H}_{2} \mathrm{O}_{2} 20 \mathrm{mM}$ was added to each well. Untreated cells with or without $\mathrm{H}_{2} \mathrm{O}_{2}$ were used as positive and negative controls, respectively. Fluorescence was measured at excitation and emission wavelengths of 485 and $530 \mathrm{~nm}$, respectively. Data were acquired at times t0 up to $120 \mathrm{~min}$. Data of the positive control $\left(\mathrm{H}_{2} \mathrm{O}_{2}\right)$ at $2 \mathrm{~h}$, were used to normalize values (\%). Background fluorescence of the negative control was subtracted from all measurements.

\section{In vitro antimicrobial efficacy}

S. epidermidis was grown overnight $37{ }^{\circ} \mathrm{C}$ in Mueller Hinton Broth (MHB) culture medium (Oxoid, Basingstoke, UK). Prior to each experiment, the inoculum was prepared in PBS adjusted to 0.5 MacFarland (McF) standard, to obtain a suspension with a cell density at the range of $1.5 \times 10^{8}$ colony forming units/mL (CFU/ $\mathrm{mL})$. Microbial count of S. epidermis was performed in TSA plates, incubated at $37^{\circ} \mathrm{C}$. The $C$. acnes was cultured in Brain Heart Infusion (BHI) medium (Oxoid, Basingstoke, UK) for $48 \mathrm{~h}$ at $37{ }^{\circ} \mathrm{C}$ under anaerobic conditions using parches (AnaeroGen ${ }^{\circledR}$, Oxoid, Basingstoke, UK) and indicator (Oxoid, Basingstoke, UK). Prior to each experiment, the inoculum was prepared in PBS adjusted to $0.5 \mathrm{McF}$. Microbial count of C. acnes was performed in clostridium reinforced medium (CRM) plates, as recommended for anaerobia growth, incubated at $37{ }^{\circ} \mathrm{C}$.

The MIC of $\mathrm{TH}$ and $\mathrm{TH}-\mathrm{NP}$ were determined using the broth microdilution assay [55]. Briefly, double concentrated sample dilutions were prepared and added $(100 \mu \mathrm{L})$ to double concentrated culture medium $(100 \mu \mathrm{L})$ in a 96-well polypropylene microtiter plate (Costar, Corning Incorporated, Corning, USA). Inocula were prepared to yield a final concentration of $5 \times 10^{5} \mathrm{CFU} / \mathrm{mL}$. For $S$. epidermidis, 10 $\mu \mathrm{L}$ were transferred to inoculate wells with final $\mathrm{TH}$ concentrations of 2 to $1024 \mu \mathrm{g} / \mathrm{mL}$, followed by incubation at $37^{\circ} \mathrm{C}$ for 18 to $20 \mathrm{~h}$. For $C$. acnes, $20 \mu \mathrm{L}$ was used to inoculate wells with concentrations ranging from 2 to $1000 \mu \mathrm{g} /$ $\mathrm{mL}$ and the plate was incubated at $37{ }^{\circ} \mathrm{C}$ for $48 \mathrm{~h}$ under anaerobiosis. Thus, the MBC was performed by transferring $10 \mu \mathrm{L}$ of each sample presenting no visible growth of C. acnes into BHI plates. These were further incubated as described before. Growth controls were used for the above experiments: presenting antimicrobial sterility (negative) and absent of antimicrobial (positive). Clindamycin was also used as an active control for both microorganisms.

The determination of the decimal reduction time assay, explores the antimicrobial activity of $\mathrm{TH}$ and its derivative TH-NP on reducing bacteria viability at determined contact times [56]. For C. acnes, formulations were diluted with water up to 250,500 and $1000 \mu \mathrm{g} / \mathrm{mL}$ representing the MIC, $2 \times \mathrm{MIC}$ and $4 \times \mathrm{MIC}$, respectively. For S. epidermidis, formulations were used at $1000 \mu \mathrm{g} /$ $\mathrm{mL}$, representing twice as MIC. Inocula were prepared in PBS at $10^{8} \mathrm{CFU} / \mathrm{mL}$ and used to inoculate $(100 \mu \mathrm{L})$ each experimental sample of $10 \mathrm{~mL}$, incubated at $32{ }^{\circ} \mathrm{C}$. The determined times were $0,1,2,3$ and $6 \mathrm{~h}$ or $0,3,8$, 24 and 48 h for $C$. acnes and $S$. epidermidis, respectively. After incubations of each time set, an aliquot of $1 \mathrm{~mL}$ of each sample was neutralized in $9 \mathrm{~mL}$ of Berens diluent (Scharlab, Barcelona, Spain) for $15 \mathrm{~min}$, then, diluted in PBS on subsequent 10-folds. Drop count method (10 $\mu \mathrm{L}$ ) was performed in CRM and TSA agar plates, for $C$. acnes and S. epidermidis, respectively, incubated at $37{ }^{\circ} \mathrm{C}$ as described previously. Bacterial viability was expressed as CFU/mL against time (h). The decimal reduction time, the time taken to reduce by $10 \%$ the initial $\log _{10} \mathrm{CFU}$, was determined calculating the inverse of the slope $(1 / b)$.

The antimicrobial activity was also evaluated by SEM. For this, C. acnes was cultured for $48 \mathrm{~h}$ in BHI culture media in an incubator shaker (Innova ${ }^{\circledR} 4080$, New Brunswick Scientific) at $37{ }^{\circ} \mathrm{C}$ under anaerobic conditions. The concentrated inoculum was transferred $(900 \mu \mathrm{L})$ to each tube containing $100 \mu \mathrm{L}$ of $\mathrm{TH}$ or $\mathrm{TH}-\mathrm{NP}$ at $0.1 \%$ or sterile 
distilled water (control) and incubated in the shaker for $1 \mathrm{~h}$. After samples were centrifuged (10,000 $\mathrm{g}$ for $5 \mathrm{~min})$, supernatants were discarded and the concentrated pellets were placed into poly-l-lysine coated coverslips and kept at room temperature for $24 \mathrm{~h}$ [57]. Samples were fixed for $4 \mathrm{~h}$ with phosphate buffer $0.1 \mathrm{M} \mathrm{pH} 7.4$, containing $4 \%$ paraformaldehyde and $2.5 \%$ glutaraldehyde, then postfixed with $1 \%$ osmium tetroxide (with potassium ferrocyanide) for $1 \mathrm{~h}$, at $4{ }^{\circ} \mathrm{C}$. After dehydration with alcohol gradients, samples were dried at critical point (Emitech K850), mounted on a conductor adhesive disc (Carbon tabs, Agar Scientific), followed by carbon coating under evaporation (Emitech 950). Images were analyzed by SEM (scanning electron microscopy, Jeol JSM-7001F).

\section{Ex vivo antimicrobial efficacy}

The bacterial viability was evaluated on treated human skin explants obtained from abdominal plastic surgery (Hospital de Barcelona, SCIAS, Barcelona, Spain), based on other researcher protocols with modifications [58]. Skin samples were cut with a cryostat (Leica Microsystems, Wetziar, Germany) in $0.6 \mathrm{~cm}^{2}$, washed with ethanol followed by sterile PBS, for 2 and $10 \mathrm{~s}$, respectively, to remove possible existing bacteria. Once dried with sterile filter paper, skins were placed into petri dishes (purchased from Fischer Scientific) with the SC facing up, onto PBS-wet sterile filter paper to keep dermis moisture. Two experiments (prevention and treatment) were set up for $24 \mathrm{~h}$ incubation at $32{ }^{\circ} \mathrm{C}$, in the presence of humidity. A fresh overnight culture of $C$. acnes was suspended in PBS $\left(1.5 \times 10^{8} \mathrm{CFU} / \mathrm{mL}\right)$ and skin samples were inoculated with $10 \mu \mathrm{L}$. For the pre-treatment study, TH-NP or $\mathrm{TH}$ were applied on skin samples $(30 \mu \mathrm{L})$ and incubated at $32{ }^{\circ} \mathrm{C}$ for $8 \mathrm{~h}$, followed by inoculation with $C$. acnes $(30 \mu \mathrm{L})$ for $16 \mathrm{~h}$. For the post-treatment study, skin was first inoculated for $30 \mathrm{~min}$ and then treated with products for $24 \mathrm{~h}$. At the end of the experiment, skin samples were neutralized in $1 \mathrm{~mL}$ Berens diluent (Scharlab, Barcelona, Spain) for neutralization (15 $\mathrm{min}$ ) followed by extraction for 10 min using a sonication bath (JP, Selecta, Spain). The extraction method was previously optimized by testing the control at two extraction times (3 to $15 \mathrm{~min}$ ), controlling bacteria viability by sonication process. Positive controls were also performed using PBS. Tenfold dilutions were performed and $100 \mu \mathrm{L}$ of each sample was spread individually onto CRM agar plates and incubated under anaerobiosis at $37^{\circ} \mathrm{C}$ for $48 \mathrm{~h}$. Viable bacteria count was expressed as $\log / \mathrm{CFU}$ per treated skin.

The analysis of bacterial viability on dose-dependent study on treated skin was also performed using the same technique as described above, with further modifications [58]. A fresh overnight culture of $C$. acnes was prepared in PBS and skin samples were inoculated $(10 \mu \mathrm{L})$. After $30 \mathrm{~min}, 30 \mu \mathrm{L}$ of $\mathrm{TH}$ or $\mathrm{TH}-\mathrm{NP}$ were administered as a single or repeated dose (1,2 or 3$)$, at preselected times $(0,12$ and $18 \mathrm{~h})$, completing a total incubation of $24 \mathrm{~h}$ at $32{ }^{\circ} \mathrm{C}$, in the presence of humidity. Then, skin samples were neutralized and extracted as described above. These were tenfold diluted and transferred to CRM plates by drop-count method (10 $\mu \mathrm{L})$. Plates were incubated under anaerobic conditions at $37^{\circ} \mathrm{C}$ for $48 \mathrm{~h}$. Viable bacteria were expressed as CFU per treated skin (Additional file 1).

A simulation of skin infection was performed in fresh human skin explant (Hospital de Barcelona, SCIAS, Barcelona, Spain) and analyzed by transmission electron microscopy. The fat tissue of skin samples, obtained from human abdominal plastic surgery, was removed manually with sterile surgical razors. Skin samples were cut and placed on a $0.64 \mathrm{~cm}^{2}$ Franz diffusion cell. The receptor compartment was filled with PBS, and the skin was inoculated with $20 \mu \mathrm{L}$ of $C$. acnes $\left(10^{8} \mathrm{CFU} / \mathrm{mL}\right)$ and incubated for $16 \mathrm{~h}$ at $32{ }^{\circ} \mathrm{C}$, followed by treatment with TH or TH-NP $(100 \mu \mathrm{L})$ for $8 \mathrm{~h}$ incubation. For electron microscopy, skin samples were fixed for $2 \mathrm{~h}$ with $4 \%$ paraformaldehyde and $2.5 \%$ glutaraldehyde in $0.1 \mathrm{M}$ sodium cacodylate buffer $(\mathrm{pH}$ 7.4), postfixed with $1 \%$ osmium tetroxide for $2 \mathrm{~h}$ at $4{ }^{\circ} \mathrm{C}$ (all from Sigma Aldrich), stained in $0.5 \%$ uranyl acetate (from Fischer Scientific) for $45 \mathrm{~min}$ at $4{ }^{\circ} \mathrm{C}$ and finally, dehydrated gradually in 30 to $100 \%$ ethanol [40]. Samples were infiltered in EPON resin [Eponate 12 $(23.5 \mathrm{~g})$, dodecenyl succinic anhydride DDSA (12.5 g) and Methyl nadic anhydride MNA (14 g)] (from Sigma Aldrich). Inclusions were performed gradually diluted in ethanol and finally for $3 \mathrm{~h}$ using a catalyst [DMP-30 (2,4,6-tris(dimethylaminomethyl)phenol), $0.37 \mathrm{~g}]$ (purchased from Sigma Aldrich). Polymerization was carried out for $48 \mathrm{~h}$ at $60{ }^{\circ} \mathrm{C}$. Blocks were sliced in thin sections with Ultracut microtome (LEICA), further fixed on copper grids and stained with uranyl acetate $2 \%$ for $10 \mathrm{~min}$. Analysis was performed by TEM and images were obtained with Megaview III.

\section{Supplementary Information}

The online version contains supplementary material available at https://doi. org/10.1186/s12951-021-01092-z.

Additional file 1: Figure S1. Morphology of TH-NP by TEM. (A) 1 month at $4{ }^{\circ} \mathrm{C}$ (B) 1 month at $25^{\circ} \mathrm{C}$ and (C) 12 months at $4{ }^{\circ} \mathrm{C}$. Arrows indicate aggregation. Scale bar: $200 \mathrm{~nm}$. Figure S2. Stability behavior of TH-NP plotted as light backscattering (\%) vs sample height, at several storage conditions: (A) $4{ }^{\circ} \mathrm{C}$ up to $12 \mathrm{~m}$, (B) $25^{\circ} \mathrm{C}$ and (C) $37^{\circ} \mathrm{C}$ up to 3 months. The scans are shown from the bottom to the top of the vial from the left to the right, as mean values of hourly measurements for $24 \mathrm{~h}$. Figure S3. Morphology of $C$. acnes observed by TEM after negative staining. Scale bar $500 \mathrm{~nm}$. 


\section{Acknowledgements}

The authors would like to acknowledge 2017SGR1477.

\section{Authors' contributions}

CF, MLG and ACC developed, participated and coordinated the experiments carried out in this study. AMM, NDG, ACC and ME have directly participated in the experimental part of this manuscript. CF, JB, LB, MLG and ESL have written, contextualized and supervised this study. All authors read and approved the final manuscript.

\section{Availability of data and materials}

Not applicable.

\section{Declarations}

\section{Ethics approval and consent to participate}

Not applicable

\section{Consent for publication}

Not applicable.

\section{Competing interests}

not applicable.

\section{Author details}

${ }^{1}$ Department of Pharmacy and Pharmaceutical Technology and Physical Chemistry, Faculty of Pharmacy and Food Sciences, University of Barcelona, 08028 Barcelona, Spain. ${ }^{2}$ Department of Biology, Healthcare and Environment, Faculty of Pharmacy and Food Sciences, University of Barcelona, 08028 Barcelona, Spain. ${ }^{3}$ Department of Biochemistry and Physiology, Biochemistry and Biomolecular Science, University of Barcelona, 08028 Barcelona, Spain. ${ }^{4}$ Institute of Biomedicine of the University of Barcelona (IBUB), 08028 BarceIona, Spain. ${ }^{5}$ Research Institute Sant Joan De Déu (IR-SJD), 08950 Barcelona, Spain. ${ }^{6}$ Institute of Nanoscience and Nanotechnology (IN2UB), University of Barcelona, 08028 Barcelona, Spain.

Received: 17 July 2021 Accepted: 17 October 2021

Published online: 08 November 2021

\section{References}

1. Kapuścińska A, Nowak I. Use of organic acids in acne and skin discolorations therapy. Postepy Hig Med Dosw. 2015;69:374-83. https://doi.org/10. 5604/17322693.1145825.

2. Kampf G, Karamer A. Epidemiologic background of hand hygiene and evaluation of the most important agents for scrubs and rubs. Clin Microbiol Rev. 2004;17(4):863-93. https://doi.org/10.1128/CMR.17.4.863.

3. Nishijima S, Kurokawa I, Katoh N, Watanabe K. The bacteriology of acne vulgaris and antimicrobial susceptibility of Propionibacterium aches and Staphylococcus epidermidis isolated from acne lesions. J Dermatol. 2000;27(5):318-23. https://doi.org/10.1111/j.1346-8138.2000.tb02174.x.

4. Otto M. Staphylococcus epidermidis - the'accidental' pathogen. Nat Rev Microbiol. 2009;7(8):557-67. https://doi.org/10.1038/nrmicro2182.

5. Ajay B, Jean-Francoise M, David HP. Propionibacterium acnes and chronic diseases - The Infectious Etiology of Chronic Diseases - NCBI Bookshelf. 2004.

6. Claudel JP, Auffret N, Leccia MT, Poli F, Corvec S, Dréno B. Staphylococcus epidermidis: a potential new player in the physiopathology of acne? Dermatology. 2019;235(4):287-94. https://doi.org/10.1159/000499858.

7. Boukraâ L, Abdellah F, Ait-Abderrahim L. Antimicrobial Properties of Bee Products and Medicinal Plants. Formatex, no. Microbial pathogens and strategies for combating them: science, technology and education. $\mathrm{p}$. 960-970; 2013

8. Alvarez-Román R, Naik A, Kalia YN, Guy RH, Fessi H. Skin penetration and distribution of polymeric nanoparticles. J Control Release. 2004;99(1):5362. https://doi.org/10.1016/j.jconrel.2004.06.015.

9. Calpena AC, Clares B, Fernández F. Technological, biopharmaceutical and pharmacokinetic advances: New formulations of application on the skin and oral mucosa. In: Muñoz-Torrero D, editor. Recent Advances in
Pharmaceutical Sciences. Kerala:Transworld Research Network; 2011. p. 175-98.

10. Shim J, Kang HS, Park WS, Han SH, Kim J, Chang IS. Transdermal delivery of mixnoxidil with block copolymer nanoparticles. J Control Release. 2004;97(3):477-84. https://doi.org/10.1016/j.jconrel.2004.03.028.

11. Wang $L$, et al. Thymol kills bacteria, reduces biofilm formation, and protects mice against a fatal infection of Actinobacillus pleuropneumoniae strain L20. Vet Microbiol. 2017;203:202-10. https://doi.org/10.1016/j. vetmic.2017.02.021.

12. Abd-Allah H, Abdel-Aziz RTA, Nasr M. Chitosan nanoparticles making their way to clinical practice: a feasibility study on their topical use for acne treatment. Int J Biol Macromol. 2020;156:262-70. https://doi.org/10. 1016/j.jijbiomac.2020.04.040.

13. Amer SS, et al. Cosm-nutraceutical nanovesicles for acne treatment: Physicochemical characterization and exploratory clinical experimentation. Int J Pharm. 2020;577:119092. https://doi.org/10.1016/j.ijpharm.2020. 119092.

14. Trombetta $D$, et al. Mechanisms of antibacterial action of three monoterpenes. Antimicrob Agents Chemother. 2005;49(6):2474-8. https://doi. org/10.1128/AAC.49.6.2474-2478.2005.

15. Guarda A, Rubilar JF, Miltz J, Galotto MJ. The antimicrobial activity of microencapsulated thymol and carvacrol. Int J Food Microbiol. 2011;146(2):144-50. https://doi.org/10.1016/j.ijfoodmicro.2011.02.011.

16. Nostro A, et al. Effects of oregano, carvacrol and thymol on Staphylococcus aureus and Staphylococcus epidermidis biofilms. J Med Microbiol. 2007;56(4):519-23. https://doi.org/10.1099/jmm.0.46804-0.

17. Yanishlieva NV, Marinova EM, Gordon MH, Raneva VG. Antioxidant activity and mechanism of action of thymol and carvacrol in two lipid systems. Food Chem. 1999;64(1):59-66. https://doi.org/10.1016/S0308-8146(98) 00086-7.

18. Wattanasatcha A, Rengpipat S, Wanichwecharungruang S. Thymol nanospheres as an effective anti-bacterial agent. Int J Pharm. 2012;434(12):360-5. https://doi.org/10.1016/j.ijpharm.2012.06.017.

19. Nagoor Meeran MF, Javed H, Al Taee H, Azimullah S, Ojha SK. Pharmacological properties and molecular mechanisms of thymol: Prospects for its therapeutic potential and pharmaceutical development. Front Pharmacol. 2017;8:1-34. https://doi.org/10.3389/fphar.2017.00380.

20. Mollarafie P, Khadiv Parsi P, Zarghami R, Amini Fazl M, Ghafarzadegan R. Antibacterial and wound healing properties of thymol (Thymus vulgaris Oil) and its application in a novel wound dressing. J Med Plants. 2015;14(53):69-81.

21. Zhang YM, Rock CO. Membrane lipid homeostasis in bacteria. Nat Rev Microbiol. 2008;6(3):222-33. https://doi.org/10.1038/nrmicro1839.

22. Najafloo R, Behyari M, Imani R, Nour S. A mini-review of Thymol incorporated materials: Applications in antibacterial wound dressing. J Drug Deliv Sci Technol. 2020. https://doi.org/10.1016/j.jddst.2020.101904.

23. Medina E, Caro N, Abugoch L, Gamboa A, Díaz-Dosque M, Tapia C. Chitosan thymol nanoparticles improve the antimicrobial effect and the water vapour barrier of chitosan-quinoa protein films. J Food Eng. 2019;240:191-8. https://doi.org/10.1016/j.jfoodeng.2018.07.023.

24. Juven BJ, Kanner J, Schved F, Weisslowicz H. Factors that interact with the antibacterial action of thyme essential oil and its active constituents. J Appl Bacteriol. 1994;76(6):626-31. https://doi.org/10.1111/j.1365-2672. 1994.tb01661.x

25. Sánchez-López E, et al. PEGylated PLGA nanospheres optimized by design of experiments for ocular administration of dexibuprofen-in vitro, ex vivo and in vivo characterization. Colloids Surfaces B Biointerfaces. 2016;145:241-50.

26. Sánchez-López E, et al. Memantine-Loaded PEGylated Biodegradable Nanoparticles for the Treatment of Glaucoma. Small. 2017; 1701808:1701808

27. Vega E, et al. Flurbiprofen PLGA-PEG nanospheres: Role of hydroxy- $\beta$ cyclodextrin on ex vivo human skin permeation and in vivo topical antiinflammatory efficacy. Colloids Surfaces B Biointerfaces. 2013;110:339-46.

28. Gómez-Segura L, Parra A, Calpena-Campmany AC, Gimeno Á, de Aranda IG, Boix-Montañes A. Ex vivo permeation of carprofen vehiculated by PLGA nanoparticles through porcine mucous membranes and ophthalmic tissues. Nanomaterials. 2020. https://doi.org/10.3390/nano10020355.

29. Kim D, El-Shall H, Dennis D, Morey T. Interaction of PLGA nanoparticles with human blood constituents. Colloids Surf B Biointerfaces. 2005;40(2):83-91. https://doi.org/10.1016/j.colsurfb.2004.05.007. 
30. Zhang X, Sun M, Zheng A, Cao D, Bi Y, Sun J. Preparation and characterization of insulin-loaded bioadhesive PLGA nanoparticles for oral administration. Eur J Pharm Sci. 2012;45(5):632-8. https://doi.org/10.1016/j.jps.2012.01.002.

31. Xiao D, Gömmel C, Davidson PM, Zhong Q. Intrinsic tween 20 improves release and antilisterial properties of co-encapsulated nisin and thymol. J Agric Food Chem. 2011;59(17):9572-80. https://doi.org/10.1021/jf201864v.

32. Cano A, et al. Epigallocatechin-3-gallate loaded PEGylated-PLGA nanoparticles: A new anti-seizure strategy for temporal lobe epilepsy. Nanomed Nanotechnol Biol Med. 2018;14(4):1073-85. https://doi.org/10.1016/..nano. 2018.01.019.

33. Abrego G, et al. Biopharmaceutical profile of pranoprofen-loaded PLGA nanoparticles containing hydrogels for ocular administration. Eur J Pharm Biopharm. 2015;95:261-70.

34. Gorzelanny C, Mess C, Schneider SW, Huck V, Brandner JM. Skin barriers in dermal drug delivery: Which barriers have to be overcome and how can we measure them? Pharmaceutics. 2020;12(7):1-31. https://doi.org/10.3390/ pharmaceutics 12070684

35. Pham QD, Björklund S, Engblom J, Topgaard D, Sparr E. Chemical penetration enhancers in stratum corneum - Relation between molecular effects and barrier function. J Control Release. 2016;232:175-87. https://doi.org/10.1016/j. jconrel.2016.04.030.

36. Akhtar N, Rehman MU, Khan HMS, Rasool F, Saeed T, Murtaza G. Penetration enhancing effect of polysorbate 20 and 80 on the in vitro percutaneous absorption of L-ascorbic acid. Trop J Pharm Res. 2011;10(3):281-8. https://doi. org/10.4314/tjpr.v10i3.1.

37. Patzelt A, Lademann J. Recent advances in follicular drug delivery of nanoparticles. Expert Opin Drug Deliv. 2020;17(1):49-60. https://doi.org/10.1080/17425 247.2020 .1700226

38. Yukuyama MN, De Araújo GLB, Bou-Chacra NA. Nanomaterials for hair care applications. Nanocosmetics. 2020. https://doi.org/10.1016/b978-0-12822286-7.00010-3.

39. Zhu Z, Min T, Zhang X, Wen Y. Microencapsulation of thymol in poly(lactideco-glycolide) (PLGA): Physical and antibacterial properties. Materials Basel. 2019;12:7. https://doi.org/10.3390/ma12071133.

40. Messager S, Hann AC, Goddard PA, Dettmar PW, Maillard JY. Use of the'ex vivo' test to study long-term bacterial survival on human skin and their sensitivity to antisepsis. J Appl Microbiol. 2004;97(6):1149-60. https://doi.org/10.1111/j. 1365-2672.2004.02403.x.

41. Erin Chen Y, Fischbach MA, Belkaid Y. Skin microbiota-host interactions. Nature. 2018;553(7689):427-36. https://doi.org/10.1038/nature25177.

42. Fessi H, Puisieux F, Devissaguet JP, Ammoury N, Benita S. Nanocapsule formation by interfacial polymer deposition following solvent displacement. Int J Pharm. 1989;55:R1-4. https://doi.org/10.1016/0378-5173(89)90281-0.

43. Gonzalez-Pizarro R, et al. Ocular penetration of fluorometholone-loaded PEG-PLGA nanoparticles functionalized with cell-penetrating peptides. Nanomedicine. 2019;14(23):3089-104. https://doi.org/10.2217/ nnm-2019-0201.

44. Sánchez-López E, et al. Dexibuprofen biodegradable nanoparticles: One step closer towards a better ocular interaction study. Nanomaterials. 2020;10(4):1-24. https://doi.org/10.3390/nano10040720.

45. Vasconcelos A, Vega E, Pérez Y, Gómara MJ, García ML, Haro I. Conjugation of cell-penetrating peptides with poly(lactic-co-glycolic acid)-polyethylene glycol nanoparticles improves ocular drug delivery. Int J Nanomedicine. 2015;10:609-31.
46. Gonzalez-Pizarro R, Silva-Abreu M, Calpena AC, Egea MA, Espina M, García ML. Development of fluorometholone-loaded PLGA nanoparticles for treatment of inflammatory disorders of anterior and posterior segments of the eye. Int J Pharm. 2018;547(1-2):338-46.

47. Sánchez-López E, et al. Memantine loaded PLGA PEGylated nanoparticles for Alzheimer's disease : in vitro and in vivo characterization. J Nanobiotechnology. 2018;16(32):1-16.

48. Ghasemi Pirbalouti A, Rahimmalek M, Malekpoor F, Karimi A. Variation in antibacterial activity, thymol and carvacrol contents of wild populations of Thymus daenensis subsp. daenensis Celak. Plant Omics. 2011;4(4):209-14.

49. Silva-Abreu M, et al. Optimization, biopharmaceutical profile and therapeutic efficacy of pioglitazone-loaded PLGA-PEG nanospheres as a novel strategy for ocular inflammatory disorders. Pharm Res. 2018;35(1):11.

50. Carvajal-Vidal P, Fábrega MJ, Espina M, Calpena AC, García ML. Development of Halobetasol-loaded nanostructured lipid carrier for dermal administration: Optimization, physicochemical and biopharmaceutical behavior, and therapeutic efficacy. Nanomed Nanotechnol Biol Med. 2019;20: 102026. https://doi. org/10.1016/j.nano.2019.102026.

51. Alvarado $\mathrm{HL}$, et al. Nanoemulsions for dermal controlled release of oleanolic and ursolic acids: In vitro, ex vivo and in vivo characterization. Colloids Surfaces B Biointerfaces. 2015;130:40-7. https://doi.org/10.1016/j.colsurfb.2015.03.062.

52. Rehman K, Aluwi MFFM, Rullah K, Wai LK, Mohd Amin MCl, Zulfakar MH. Probing the effects of fish oil on the delivery and inflammation-inducing potential of imiquimod. Int J Pharm. 2015;490(1-2):131-41. https://doi.org/10.1016/j. ijpharm.2015.05.045.

53. Diaz-Garrido N, Fábrega MJ, Vera R, Giménez R, Badia J, Baldomà L,"Membrane vesicles from the probiotic Nissle, and gut resident Escherichia coli strains distinctly modulate human dendritic cells and subsequent T cell responses". J Funct Foods. 1917. https://doi.org/10.1016/j.jff.2019.103495.

54. Liu YH, Lin YS, Huang YW, Fang SU, Lin SY, Hou WC. Protective Effects of Minor Components of Curcuminoids on Hydrogen Peroxide-Treated Human HaCaT Keratinocytes. J Agric Food Chem. 2016;64(18):3598-608. https://doi.org/10. 1021/acs.jafc.6b01196.

55. Koeth LM, Miller LA. Antimicrobial susceptibility test methods: dilution and disk diffusion methods. In: Carroll KC, Pfaller MA, Landy ML, Patel R, McAdam AJ, Richter S, editors. Manual of Clinical Microbiology. 12th ed. Washington D C: ASM Press; 2019. p. 1284-99.

56. MacGowan AP, Wootton M, Hedges AJ, Bowker KE, Holt HA, Reeves DS. A new time-kill method of assessing the relative efficacy of antimicrobial agents alone and in combination developed using a representative $\beta$-lactam, aminoglycoside and fluoroquinolone. J Antimicrob Chemother. 1996:38(2):193-203. https://doi.org/10.1093/jac/38.2.193.

57. Mazia D, Schatten G, Sale W. Adhesion of cells to surfaces coated with polylysine: Applications to electron microscopy. J Cell Biol. 1975;66(1):198-200. https://doi.org/10.1083/jcb.66.1.198.

58. Messager S, Goddard PA, Dettmar PW, Maillard JY. Determination of the antibacterial efficacy of several antiseptics tested on skin by an 'ex-vivo' test. J Med Microbiol. 2001;50(3):284-92. https://doi.org/10.1099/ 0022-1317-50-3-284.

\section{Publisher's Note}

Springer Nature remains neutral with regard to jurisdictional claims in published maps and institutional affiliations.

\footnotetext{
Ready to submit your research? Choose BMC and benefit from:

- fast, convenient online submission

- thorough peer review by experienced researchers in your field

- rapid publication on acceptance

- support for research data, including large and complex data types

- gold Open Access which fosters wider collaboration and increased citations

- maximum visibility for your research: over 100M website views per year
}

At BMC, research is always in progress.

Learn more biomedcentral.com/submissions 